\title{
Tutela contra laudos arbitrales: hacia una solución en el arbitraje local e internacional
}

DOI: http://dx.doi.org/10.15425/2017.509

\section{Resumen}

La acción de tutela contra laudos arbitrales es una realidad en los arbitrajes locales e internacionales con sede en Colombia. La Corte Constitucional ha confirmado la supremacía normativa y la aplicación territorial de la Constitución a las decisiones de los árbitros, reafirmando la procedencia de la tutela. Sin embargo, su jurisprudencia ha equiparado los laudos a las sentencias judiciales, sin aplicar las diferencias que la propia Corte ha trazado entre aquellos y estas en sus fallos. El artículo cuestiona, en forma constructiva, los requisitos actuales de procedencia de la acción de tutela contra los laudos en casos locales e internacionales. Propone una nueva metodología de análisis de la tutela para el arbitraje local e internacional, en la cual se reconozca el principio constitucional de la habilitación, de manera real y efectiva, y se tutele la autonomía de las partes al pactar el arbitraje.

\section{Palabras clave}

Arbitraje nacional, arbitraje internacional, laudo arbitral, acción de tutela, Constitución Política, Corte Constitucional, Corte Suprema de Justicia, orden público internacional, derecho sustancial aplicable, vías de hecho, principio de habilitación, Ley 1563 del 2012.

Abogado y especialista en Derecho Comercial de la Universidad de los Andes. LL.M. en International Business Law, con mención de honor en The London School of Economics and Political Science. Árbitro de la Cámara de Comercio de Bogotá y de otras instituciones arbitrales. Árbitro internacional. Autor del libro Arbitraje comercial internacional: instituciones básicas y derecho aplicable, publicado por Temis y Ediciones Uniandes. Profesor de cátedra, en pregrado y posgrado, en la Universidad de los Andes y en otras universidades nacionales y extranjeras. Ha intervenido como árbitro y apoderado de parte en múltiples casos de arbitraje local e internacional. Es socio de la firma Talero Rueda \& Asociados. Correos: stalero@talerolegal.com; stalero@cable.net.co 


\title{
Constitutional claim against arbitration awards: Towards a solution in domestic and international arbitration
}

\begin{abstract}
The acción de tutela or constitutional claim, against arbitration awards in domestic and international arbitrations seated in Colombia, has been upheld by the country's case law. The Constitutional Court has confirmed the Constitution's superior hierarchy and its territorial application regarding the arbitrators' decisions, thereby reaffirming the feasibility of the tutela. Its case law has equated the arbitration awards to the judicial decisions, but has overlooked the differences that the Court itself has in fact identified between the former and the latter. This article revisits, in a constructive way, the current requirements applicable to the acción de tutela regarding arbitration awards in domestic and international cases. It proposes a new analytical methodology regarding the tutela, applicable to domestic and international arbitrations, according to which the so-called constitutional principle of empowerment or habilitación must be effectively observed and the parties' autonomy in arbitration must be protected.
\end{abstract}

\section{Keywords}

Domestic arbitration, international arbitration, arbitration award, constitutional claim, Constitutional Court, Supreme Court of Justice, international public policy, applicable substantive law, gross judicial mistakes, principle of empowerment, Law 1563 of 2012. 


\section{Introducción}

Al someter sus controversias actuales o futuras al arbitraje, las partes renuncian a resolverlas ante los jueces estatales. Dicha libertad contractual, plasmada en un pacto arbitral, implica acudir a un mecanismo de solución de controversias de única instancia, mediante el cual se busca que la decisión de los árbitros sea definitiva y vinculante.

El pacto arbitral implica entonces una consecuencia positiva y otra negativa ${ }^{1}$. La primera es una obligación de hacer, que consiste en acudir a un mecanismo particular de solución de controversias. La segunda, que es un reflejo de la primera, se concreta en un deber de abstención. Este consiste en renunciar a resolver las diferencias ante la justicia ordinaria del Estado, con las distintas consecuencias que ello conlleva².

Así, el consentimiento entre las partes ha sido tradicionalmente la piedra angular del arbitraje, al menos en aquellos Estados en los cuales se restringe o se limita el llamado "arbitraje obligatorio" —o por ministerio de la ley_ para resolver determinadas controversias ${ }^{3}$. Este punto de partida es conocido en algunas jurisdicciones como principio de habilitación. Según dicho principio, que en Colombia tiene rango constitucional 4 , "[...] es la voluntad de las partes en conflicto, potencial o actual, la que habilita a los árbitros para actuar"5. De este modo, el pacto arbitral será la expresión o materialización de dicha voluntad habilitante, que marca y

Véase, entre otros: Gary Born, International commercial arbitration, vol. 1 (Kluwer Law International, 2009), 1003-1056; Eduardo Silva Romero, "Una obligación de hacer: someter el litigio al arbitraje"; y "Una obligación de no hacer: no someter los litigios a la jurisdicción estatal”, en El contrato de arbitraje (Bogotá: Legis, Universidad del Rosario, 2005), 525-527 y 695-697; y Santiago Talero Rueda, "Extensión del pacto arbitral a no signatarios: perspectivas en la nueva Ley Peruana de Arbitraje", Lima Arbitration n. ${ }^{\circ} 4$ (2010-2011): 72.

2 Esta renuncia no es absoluta, pues las cortes judiciales pueden asistir el proceso arbitral de distintas maneras, incluyendo hacer efectivas medidas cautelares. De hecho, se ha sostenido que la relación entre los tribunales arbitrales y las cortes judiciales se puede catalogar como una "carrera de relevos": Lord Mustill. "Comments and Conclusions". Conservatory \& provisional measures in international arbitration. 9th Joint Colloquium. Publicación CCI 519, 1993.

Así, por ejemplo, la jurisprudencia en Estados Unidos ha sostenido que un sujeto no puede ser sometido al arbitraje cuando aquel no ha convenido someter la respectiva controversia al mencionado mecanismo: United Steel Workers of America v. Warrior and GulfNavigation Co., 36 US 574,582 (1960). 
delimita la actuación de los tribunales arbitrales, y denota la renuncia de las partes a dirimir sus diferencias ante la justicia ordinaria ${ }^{6}$.

Una perspectiva mixta sobre la naturaleza del arbitraje nos indica entonces que este tiene un origen contractual, plasmado en el pacto arbitral. El objeto de dicho pacto arbitral, a su turno, sería un acto jurisdiccional, que es, en últimas, un laudo arbitral en el que se resuelven las controversias entre las partes ${ }^{7}$.

Los lineamientos anteriores apuntarían a que los laudos arbitrales, a diferencia de lo que ocurre con las sentencias judiciales en general, fueran ajenos a las revisiones judiciales de fondo o in judicando, las cuales se instrumentan comúnmente, en el ámbito judicial, a partir del denominado recurso de apelación. De hecho, la impugnación de los laudos se circunscribe a otro recurso, el de anulación, tanto en el ámbito local como internacional. Este es el único mecanismo judicial para impugnar los laudos arbitrales. El recurso tiene carácter garantista, pues se circunscribe a verificar si el arbitraje se ha desarrollado o no con sujeción a los principios rectores de un debido proceso. De ahí que los laudos arbitrales, por regla general, sean susceptibles de anulación por errores de procedimiento - in procedendo- y no por errores de tipo sustancial — in judicando-. Se ha sostenido, en consecuencia, que la decisión judicial sobre la validez o la nulidad del laudo arbitral, no puede llegar a sustituir la decisión de fondo adoptada por los árbitros ${ }^{8}$.

Sin embargo, la realidad ha ido más allá. De tiempo atrás, en distintos países de Iberoamérica se ha reconocido la posibilidad de cuestionar la validez de los laudos arbitrales a la luz del ordenamiento constitucional, a partir del denominado recurso de amparo, conocido en Colombia, con algunas diferencias, como acción de tutela9.

6 Tal como oportunamente lo señalase la jurisprudencia constitucional colombiana, "[...] si los laudos fueran apelables ante los jueces, la disputa cuya resolución las partes voluntariamente decidieron confiar a unos particulares habilitados por ellas terminaría siendo desatada precisamente por el sistema estatal de administración de justicia de la cual las partes, en ejercicio de su autonomía contractual y de la facultad reconocida en el artículo 116 de la Constitución, querían sustraer esas controversias específicas en virtud de una cláusula compromisoria o de un compromiso". Corte Constitucional de Colombia: Sentencia SU-174 del 2007.

7 Santiago Talero Rueda, Arbitraje comercial internacional: instituciones básicas y derecho aplicable (Bogotá: Temis, Ediciones Uniandes, 2008), 16-21. En efecto, los árbitros administran justicia por la habilitación de las partes, la cual se encuentra en el pacto arbitral. A su vez, la "[...] la jurisdicción es la facultad de administrar justicia".: Corte Suprema de Justicia de Colombia. Sala de Casación Civil. Sentencia del 28 de febrero de 1968. G. J. XLVII.

8 Rafael Hinojosa, "La impugnación del laudo en la ley española del 2003", Revista Peruana de Arbitraje vol. 3 (2006): 374.

9 Algunos antecedentes relevantes del amparo contra laudos se encuentran, entre otros, en Alfredo de Jesús, "La Sala Constitucional y el arbitraje comercial: hacia un régimen racional del control judicial del laudo arbitral en el derecho venezolano", Revista Peruana de Arbitraje vol. 3 (2006): 64 y ss.; Jaime David Abanto, "El arbitraje en las sentencias del tribunal constitucional y la procedencia 
La acción de tutela plantea entonces un interrogante sobre el carácter definitivo y vinculante de los laudos arbitrales, así como de la eficacia de los medios consagrados para su impugnación, particularmente del recurso de anulación.

Colombia no ha sido ajena a esta situación. De hecho, la Corte Constitucional ha proferido múltiples fallos sobre el arbitraje en general, incluyendo la tutela contra decisiones arbitrales ${ }^{10}$. Así, la Corte ha construido una doctrina sobre la procedencia de la tutela frente al arbitraje local, pero recientemente se pronunció sobre una acción de tutela contra un laudo emanado de un arbitraje internacional con sede en Colombia ${ }^{11}$.

La procedencia de la tutela contra laudos ha generado múltiples inquietudes en la comunidad jurídica y empresarial. Una de ellas apunta a la estabilidad jurídica de las decisiones arbitrales, dado que dichas decisiones, en un momento dado, podrían ser sustituidas por el criterio del juez estatal del cual las partes, en ejercicio de su autonomía privada, se habían querido sustraer.

El propósito de este artículo es revisar los puntos álgidos que plantea la tutela contra laudos arbitrales en Colombia, incluyendo una propuesta para mejorar su desarrollo en el futuro. A partir de ahí, se analizarán las razones por las cuales el principio constitucional de habilitación es la herramienta fundamental para encauzar o redirigir las acciones de tutela contra decisiones arbitrales, tanto en arbitrajes locales como en internacionales con sede en el país. Se propondrá entonces que la propia Corte Constitucional retome algunos elementos de su jurisprudencia y replantee otros, con miras a articular un mecanismo de impugnación de laudos que responda al principio de supremacía normativa de la Constitución Política, pero que consulte, al mismo tiempo, la naturaleza del arbitraje y las expectativas legítimas de sus intervinientes.

del recurso de amparo contra laudos arbitrales", Revista Peruana de Arbitraje vol. 3 (2006): 147 y ss.; Jorge Santistevan de Noriega, "Arbitraje y jurisdicción desde la perspectiva del Tribunal Constitucional del Perú", Revista Peruana de Arbitraje vol. 3 (2006): 47; Alejandro Follonier-Ayala, "Constitucionalización del arbitraje en América Latina", Revista del Club Español de Arbitraje (2015): 107-134; Bernardo Cremades, "El arbitraje en la doctrina constitucional española”. Lima Arbitration n. 1 (2006): 185-220; y Jesús Remón, "La anulación del laudo: el marco general, el pacto de exclusión y el orden público”, Revista del Club Español de Arbitraje (2006): 115-132.

Véase, entre muchas otras: Corte Constitucional de Colombia. Sentencias C-242 de 1997; C-347 de 1997; C-330 del 2000; C-590 del 2005; SU-174 del 2007; T-244 del 2007; C-378 del 2008; SU-033 del 2008; T-058 del 2009; T-466 del 2011; SU-500 del 2015; y SU-556 del 2016. Un interesante análisis sobre la evolución de la acción de tutela contra laudos arbitrales, se encuentra en Jorge Enrique Ibáñez, La acción de tutela contra laudos arbitrales (Bogotá: Pontificia Universidad Javeriana, De Palma y Grupo Editorial Ibáñez, 2009).

11 Corte Constitucional de Colombia. Sentencia T-354 del 2019. En la Sentencia SU-500 del 2015, la Corte resolvió una tutela contra un laudo en un arbitraje internacional, pero en dicho caso desplegó su análisis conforme a su doctrina sobre la procedencia de la tutela frente a laudos en arbitrajes nacionales. 


\section{La tutela contra los laudos arbitrales es una realidad}

En la comunidad arbitral, con frecuencia se señala que la acción de tutela no debe proceder contra los laudos arbitrales. Este planteamiento es claro, legítimo y razonable. La tutela contra laudos, en muchas circunstancias, se emplea como recurso de instancia y pone en entredicho la estabilidad jurídica de las decisiones arbitrales e incluso las expectativas de las propias partes, quienes pactan el arbitraje para sustraerse a un fallo de fondo por parte de la justicia ordinaria del Estado.

Sin embargo, la Corte Constitucional de Colombia ha puntualizado que no es posible introducir limitaciones al ejercicio de las acciones de tutela, aún si ello se hiciera mediante reformas constitucionales ${ }^{12}$. De este modo, parecería que una reforma normativa, de rango constitucional, que clausurare la viabilidad de la tutela contra los laudos, no necesariamente lograría este cometido, tal como lo ha advertido la misma Corte Constitucional.

En términos generales, y al reconocer la procedencia de la tutela contra laudos, la corte ha refrendado la supremacía normativa de la Constitución Política y su ámbito objetivo y territorial de aplicación frente a arbitrajes con sede en Colombia ${ }^{13}$, para así materializar el principio de efectividad de los derechos fundamentales ${ }^{14}$.

Así, por ejemplo, la Corte se pronunció sobre si los jueces de tutela podrían o no intervenir en arbitrajes internacionales con sede en Colombia. En efecto, el artículo 67 de la Ley 1563 del 2012 señala que, en los asuntos cobijados por la sección de arbitraje internacional de esta ley, ninguna autoridad judicial puede intervenir salvo en aquellos casos en que dicha sección expresamente lo disponga ${ }^{15}$. La norma, de rango legal, parecería aislar el régimen del arbitraje internacional frente al control constitucional por vía de tutela. Con todo, la Corte rechazó dicha lectura exegética al afirmar que el

12 Corte Constitucional de Colombia. Sentencia T-354 del 2019, refiriéndose a la Sentencia C-674 del 2017.

13 Artículos 4, 6 y 95 de la Constitución Política. La jurisprudencia peruana, por ejemplo, también ha refrendado la sujeción del arbitraje a la Constitución Política de dicho país, pese a que allí se considera al arbitraje como una jurisdicción independiente del poder judicial. El Tribunal Constitucional del Perú, en sentencia del 11 de septiembre del 2011, proferida en el caso María Julia, sostuvo que “[...] la especial naturaleza del arbitraje, en tanto autonomía de la voluntad de las partes y, al mismo tiempo, de la independencia de la jurisdicción arbitral, no supone en lo absoluto desvinculación del esquema constitucional, ni mucho menos del cuadro de derechos y principios reconocidos por la Constitución".

15 La Ley 1563 del 2012, en su sección tercera, incorpora los lineamientos de la Ley Modelo de Uncitral sobre Arbitraje Comercial Internacional, con algunos ajustes. 
[...] derecho a la tutela judicial efectiva en su dimensión constitucional es jerárquicamente superior a la ley, razón por la que el legislador no puede limitar la posibilidad reconocida a todas las personas de acudir ante los jueces para asegurar la protección o el restablecimiento de sus derechos ni la competencia de los jueces para conocer de las acciones previstas en la Constitución para tal efecto, como es la tutela [...] no se ha vedado la intervención de los jueces constitucionales ni tampoco se han excluido los laudos internacionales del ámbito objetivo de la acción de tutela ${ }^{16}$.

La aplicación territorial de la Constitución, en materia arbitral, ya había sido avalada por la propia Corte. Durante la vigencia de la ya derogada Ley 315 de 1996, la Corte se pronunció sobre la exequibilidad de uno de los criterios de internacionalidad del arbitraje contenidos en dicha ley, según el cual un arbitraje sería internacional si la sede del arbitraje se encontraba fuera del Estado en que las partes tienen sus domicilios, siempre que se hubiera pactado tal eventualidad en el pacto arbitral ${ }^{17}$. En su decisión mayoritaria, la Corte declaró la constitucionalidad condicionada de la norma. Tras un escueto análisis, sostuvo que el pacto de sede extranjera solo sería viable si la controversia involucrara un elemento extranjero, como lo sería, según la misma Corte, el hecho de que una de las partes tuviera nacionalidad extranjera. El salvamento de voto, a su vez, fue mucho más allá que el fallo principal y efectuó precisiones importantes ${ }^{18}$. Sobre este punto, aclaró que la libertad de las partes, para pactar sede extranjera, solo podría desplazar la aplicación territorial de la Constitución Política en la medida en que hubiera elementos objetivos de internacionalidad en el negocio que así lo justificaran. El salvamento también sostuvo, en forma expresa, que el simple pacto de sede extranjera, sin elementos objetivos de internacionalidad que lo sustentaran, constituiría una posible evasión o un fraude a la ley nacional ${ }^{19}$. De este modo, concluyó que la norma reñiría

Corte Constitucional de Colombia. Sentencia T-354 del 2019.

Este criterio de internacionalidad del arbitraje corresponde a aquel consagrado en el artículo 1(3) (b)(i) de la Ley Modelo de Uncitral.

Corte Constitucional de Colombia. Sentencia C-347 de 1997. Salvamento de Voto del magistrado Eduardo Cifuentes.

La sanción del fraude a la ley se ha concebido como mecanismo de protección del contratante débil. En sentido estricto, el fraude a la ley consiste en hacer operar una regla de derecho para impedir o desviar la aplicación de otra regla. Para que opere el fraude, se requeriría (1) una regla obligatoria -i. e. la sentencia de la Corte Constitucional-; (2) la intención de eludir la regla obligatoria, conforme a los fines perseguidos y sin que se deba probar la intención específica de eludirla -i. e. el pacto de sede extranjera ajena a una parte y afín a la otra, ignorando la falta de elementos de internacionalidad-; y (3) el empleo de un medio idóneo para eludir la regla obligatoria - el ejercicio de la libertad contractual, propia del derecho arbitral, plasmada en la estipulación de sede arbitral extranjera-. Los alcances generales de dicha figura del fraude a la ley, se explican en: Jorge Suescún, Derecho privado: estudios de derecho civil y comercial contemporáneo, t. II (Bogotá: Legis, Ediciones Uniandes, 2003), 241-246. 
con el principio de aplicación territorial de la Constitución Política, al igual que con el derecho fundamental a una tutela judicial efectiva en Colombia y con el derecho a la igualdad. Este fallo, incluyendo su salvamento, propició la eliminación de dicho criterio de internacionalidad del arbitraje en la legislación colombiana, tal como se observa en el artículo 62 de la Ley 1563 del 2012.

Los lineamientos anteriores sirven para despejar otra inquietud sobre la posible improcedencia de la tutela contra laudos arbitrales. Se ha sugerido, en consonancia con otras jurisdicciones nacionales, que los árbitros, principalmente en el arbitraje internacional, no son jueces $y$, por ende, no cabe la tutela contra los laudos como sí ocurre respecto de las sentencias judiciales ${ }^{20}$.

La Corte Constitucional no ha abordado este interrogante, al menos en forma expresa. Sin embargo, la propia Corte ya lo habrían evacuado al interpretar el régimen legal aplicable. En efecto, el artículo 42, numeral 8, del Decreto 2591 de 1991, señala que en Colombia procede la tutela contra particulares cuando ejercen una función pública ${ }^{21}$. La Corte ha sostenido que en

[...] la función pública de administrar justicia, los árbitros deben estar habilitados por las partes en conflicto, en cada caso concreto [...] El ejercicio arbitral de la función pública de administrar justicia se hace en forma transitoria y excepcional, dado el propósito y finalidad consistente en la solución en forma amigable de un determinado conflicto, por lo que las funciones de los árbitros terminan una vez proferido el laudo arbitral22.

Así,

[...] mientras las autoridades judiciales realizan una función pública institucional, inherente a la existencia misma del Estado, los árbitros desempeñan esa función en virtud de la habilitación que les han conferido en ejercicio de la autonomía de su voluntad contractual las partes que se enfrentan en un conflicto determinado ${ }^{23}$.

De hecho, en su aclaración de voto frente a la sentencia T-354 del 2019, el magistrado Antonio José Lizarazo señaló que los árbitros, tratándose de arbitrajes internacionales, no necesariamente ejercen funciones jurisdiccionales. Este planteamiento sugiere que la decisión mayoritaria, por lo menos en forma tácita, habría acogido la tesis de que los árbitros ejercen funciones jurisdiccionales en el arbitraje internacional.

21 En la referida aclaración de voto, el magistrado Antonio José Lizarazo, al reafirmar la procedencia marcadamente excepcional de la acción de tutela contra laudos arbitrales en arbitrajes internacionales, sostuvo que ello era posible, entre otras razones, debido al "[...] ámbito objetivo de la acción de tutela, el cual comprende acciones u omisiones de particulares.". 
De este modo, para la Corte los árbitros son particulares que ejercen transitoriamente la función pública de administrar justicia, situación que, a su vez, respaldaría la procedencia de la tutela contra sus decisiones.

En consonancia con lo anterior, parecería que el status jurídico del árbitro, en países como Colombia, no ha sido el criterio decisivo para descartar la acción de tutela frente a sus decisiones ${ }^{24}$. En su lugar, la Corte Constitucional ha adoptado, en forma sistemática, una posición territorialista del arbitraje. Con base en ello, ha defendido el ámbito objetivo de aplicación de la Constitución, situación que abarca los laudos proferidos en arbitrajes locales e internacionales con sede en Colombia, independientemente de si los árbitros son considerados jueces o particulares. $Y$, en todo caso, frente a esta última condición - la de ser particulares-, la Corte ha inclinado la balanza hacia el hecho de que los laudos arbitrales hacen tránsito a cosa juzgada, y no tanto hacia el origen contractual de la función arbitral, razón por la

En otros países, como México, se ha considerado que las decisiones arbitrales no son objeto, al menos en forma directa, de un recurso de amparo. La razón para ello radica en que en dicho país el amparo procede contra actos de "autoridades" y se considera que los árbitros no tienen este carácter. En tal sentido, se reconoce que el origen privado y contractual del arbitraje, basado en la voluntad de las partes, distingue a los árbitros de las denominadas "autoridades responsables". Véase, por ejemplo, Cuarto Tribunal Colegiado en Materia Civil de México. Exp. DC 4/2014. Caso Conproca; Francisco González de Cossío, "Mexico's fantastic three: A pro-arbitration trilogy ", Arbitration International n. 33 (2017), 158; y Cecilia Flores, "Precedente judicial: los árbitros no son considerados como autoridad para efectos del juicio de amparo”, Revista del Club Español de Arbitraje (2018): 133-136. Sin embargo, el amparo puede afectar los laudos arbitrales en México, una vez los jueces estatales profieran fallos en los cuales se resuelva sobre impugnaciones a dichos laudos. En otras palabras, el amparo se termina dirigiendo contra los fallos judiciales que mantienen en firme los laudos arbitrales, dado que dichos fallos sí se consideran actos de autoridad: Francisco González de Cossío, "National Report for Mexico (2018 through 2019)", ICCA International Handbook on Commercial Arbitration (Kluwer Law International \& ICCA, 2020), 40-41. En países como España, el amparo procede contra la decisión judicial que resuelve el recurso de anulación del laudo, pues se ha sostenido que el laudo no emana de un poder público y resulta extraño al ámbito del proceso constitucional de amparo: Tribunal Constitucional español. Sentencia 176/1996 del 11 de noviembre de 1996. Como rechazo a la asimilación de los árbitros a los jueces en Colombia, se ha sostenido que el artículo 116 de la Constitución Política no fue concebido para los árbitros en arbitrajes internacionales. Se dice que esta situación se evidencia, entre otras cosas, en los requisitos previstos para ser árbitro por la sección de arbitraje nacional contenida en la Ley 1563 del 2012 - i. e. reunir los mismos requisitos para ser magistrado de Tribunal Superior de Distrito Judicial-, los cuales son ajenos a la dinámica propia del arbitraje internacional y responden a la ubicación del arbitraje como una parte de la organización del Estado colombiano en el texto constitucional: Bernardo Salazar, "Tutela contra laudos arbitrales en Colombia”, Arbitraje y Constitución, vol. 1 (Asociación Latinoamericana de Arbitraje, 2020-2021), 151-152. En países como Argentina, la posible asimilación de árbitros y jueces carece de relevancia frente al amparo constitucional. Se ha señalado que "[...] si bien los árbitros no se confunden con los jueces ni pertenecen formal ni materialmente al Poder Judicial, el razonamiento que ha conducido a la admisión de la acción de tutela constitucional contra los laudos arbitrales en los países latinoamericanos (esto es, la asimilación material de la actividad de los árbitros a la de los jueces, contra la cuales procede la acción de amparo constitucional) no encuentra cabida en el derecho argentino que, contrariamente a lo que sucede en esos otros ordenamientos, consagra expresamente la inadmisibilidad de la acción de amparo cuando '[e]l acto impugnado emanara de un órgano del Poder Judicial'. De ello se deriva que no es posible cuestionar a través del amparo la sentencia judicial que decidió sobre la anulación de un laudo arbitral": Roque Caivano. "Arbitraje y constitución", Arbitraje y Constitución vol. 1 (Asociación Latinoamericana de Arbitraje, 2020-2021), 66. 
cual ha reiterado que los árbitros, pese a ser particulares, despliegan la función pública de administrar justicia en forma transitoria.

De este modo, en criterio de la Corte Constitucional, la acción de tutela contra laudos es procedente cuando un arbitraje tenga su sede en el país.

\section{Marco general de la procedencia de la acción de tutela contra laudos arbitrales}

Al abordar el artículo 116 de la Constitución, la Corte Constitucional ha dicho que el laudo arbitral es, en últimas, un acto jurisdiccional que hace tránsito a cosa juzgada ${ }^{25}$.

Así, la jurisprudencia nacional ha considerado procedente la acción de tutela, frente a decisiones arbitrales y judiciales, dado que unas y otras emergen de la función de administrar justicia y pueden llegar, en la práctica, a lesionar derechos fundamentales ${ }^{26}$.

La equivalencia material entre los laudos y las sentencias judiciales, ha sido descrita por la Corte Constitucional así:

En síntesis, el proceso arbitral es materialmente un proceso judicial, y el laudo arbitral es el equivalente a una sentencia judicial en la medida que pone fin al proceso y desata de manera definitiva la cuestión examinada, adicionalmente los árbitros son investidos de manera transitoria de la función pública de administrar justicia, la cual además legalmente ha sido calificada como un servicio público, por tal razón no cabe duda que en sus actuaciones y en las decisiones que adopten los tribunales arbitrales están vinculados por los derechos fundamentales, y que la tutela es procedente cuando estos sean vulnerados o amenazados con ocasión de un proceso arbitral ${ }^{27}$.

Sin embargo,

[...] mientras las autoridades judiciales realizan una función pública institucional, inherente a la existencia misma del Estado, los árbitros desempeñan esa función en virtud de la habilitación que les han conferido en ejercicio de la autonomía de su voluntad contractual las partes que se enfrentan en un conflicto determinado ${ }^{28}$.

Corte Constitucional de Colombia. Sentencia SU-033 del 2018.

Véase, entre otras: Corte Constitucional de Colombia: Sentencias T-244 del 2007; y SU-500 del 2015.

Corte Constitucional de Colombia. Sentencia T-244 del 2007.

Corte Constitucional. Sentencia C-378 del 2008. 
Según el principio constitucional de habilitación, los laudos arbitrales carecen de segunda instancia y la tutela, en este contexto, tiene una procedencia verdaderamente excepcional. La jurisprudencia constitucional ha sostenido entonces que

[...] si los laudos fueran apelables ante los jueces, la disputa cuya resolución las partes voluntariamente decidieron confiar a unos particulares habilitados por ellas terminaría siendo desatada precisamente por el sistema estatal de administración de justicia de la cual las partes, en ejercicio de su autonomía contractual y de la facultad reconocida en el artículo 116 de la Constitución, querían sustraer esas controversias específicas en virtud de una cláusula compromisoria o de un compromiso ${ }^{29}$.

La Corte Suprema de Justicia, a su vez, ha sostenido que

[...] el juez de tutela no es el llamado a intervenir a manera de árbitro para determinar cuáles de los planteamientos valorativos y hermenéuticos del juzgador, o de las partes, resultan ser los más acertados, y menos acometer, bajo ese pretexto, como lo pretende la actora, la revisión oficiosa del asunto, como si fuese uno de instancia ${ }^{30}$.

La equivalencia entre laudos y sentencias es entonces relativa. La acción de tutela contra sentencias "[...] solo puede proceder si se cumplen ciertos y rigurosos requisitos de procedibilidad" ${ }^{11}$, al paso que

[...] el carácter especial de la justicia arbitral implica que se deba hacer un examen de procedibilidad - tanto de los requisitos generales como especiales- más estricto [...] se está en un escenario en el cual se ha expresado la voluntad de los sujetos de apartarse de la jurisdicción ordinaria y someterse a la decisión que adopte un tribunal de arbitramento. Ello, por cuanto "[...] acudir a la justicia arbitral implica una derogación específica, excepcional y transitoria de la administración de justicia estatal, derivada de la voluntad de las partes en un conflicto transigible" ${ }^{\prime 32}$.

Corte Constitucional de Colombia. Sentencia SU-174 del 2007.

30 Véase, entre otras: Corte Suprema de Justicia de Colombia. Sala de Casación Civil. Sentencia del 25 de enero del 2017, donde se cita el aparte transcrito y otros de la misma corporación para destacar el carácter marcadamente excepcional de la tutela contra decisiones arbitrales.

31 Corte Constitucional de Colombia. Sentencia C-590 del 2005.

32 Corte Constitucional de Colombia. Sentencia SU-500 del 2015, refiriéndose a la Sentencia SU-174 del 2007. 
No en vano, al juez constitucional se le restringe la posibilidad de "[...] revisar in integrum la determinación definitiva adoptada por los árbitros, ya que aquella se reputa prima facie intangible, definitiva y revestida de plenos efectos de cosa juzgada"33.

En consonancia con lo anterior, el carácter claramente excepcional de la tutela contra laudos arbitrales se ha sustentado, entre otros, en el principio de habilitación, en la estabilidad jurídica de los laudos, y en "[...] el margen de decisión autónoma de los árbitros, que no debe ser invadido por el juez de tutela y le impide a este, pronunciarse directamente sobre el fondo del asunto sometido a arbitramento" ${ }^{34}$.

Teniendo ello en mente, la jurisprudencia nacional ha dispuesto dos tipos de requisitos de procedencia de la acción de tutela para sentencias y laudos en casos de arbitraje nacional: (1) los requisitos generales de procedibilidad o admisibilidad de la acción; y (2) los requisitos específicos de procedencia del amparo solicitado ${ }^{35}$. Los primeros tienen alcance procesal, mientras que los segundos tienen alcance sustantivo, pues recogen las denominadas vías de hecho y se refieren específicamente al amparo solicitado en cada caso ${ }^{36}$.

En consecuencia, para que proceda la tutela contra laudos arbitrales

[...] deberán reunirse los requisitos generales de procedencia y los requisitos especiales de procedibilidad de la acción tutela contra providencias judiciales que han sido fijados por esta Corporación [...] la Corte sostiene que para que la tutela contra de una decisión judicial sea procedente y, por ende, para que pueda prosperar se deben verificar, respectivamente, la presencia de unas causales genéricas y otras específicas, además de la violación a un derecho fundamental”37.

Corte Constitucional de Colombia, Sentencia T-466 del 2011.

Corte Constitucional de Colombia. Sentencias SU-174 del 2007; y SU-033 del 2008.

Corte Constitucional de Colombia. Sentencias C-590 del 2005; y SU-817 del 2010.

Ibid.

Corte Constitucional de Colombia. Sentencia SU-817 del 2010. En países como Perú, el Tribunal Constitucional ha revisado su jurisprudencia para afinar los requisitos de procedencia del amparo contra laudos arbitrales. Esto ocurrió en su sentencia del 11 de septiembre del 2011, proferida en el caso María Julia. Allí, el referido tribunal señaló que el amparo procedería si el caso concreto plantease (1) la violación directa de los precedentes vinculantes establecidos por el Tribunal Constitucional; (2) el ejercicio, dentro del laudo, del denominado control difuso sobre una norma declarada exequible por dicho tribunal o por el poder judicial; o (3) la afectación directa y manifiesta, generada por el laudo, respecto de los derechos constitucionales de un tercero ajeno al pacto arbitral del caso concreto, y que no tenga la calidad de parte no signataria de este. 


\subsection{Causales generales de procedibilidad de la acción de tutela contra laudos}

Dichas causales, que determinan la admisibilidad de la acción de tutela, se sintetizan así3:

- La cuestión discutida debe tener una evidente relevancia constitucional. Se debe explicar por qué el caso concreto tiene esta connotación, dado que el juez de tutela no podrá involucrarse en asuntos que sean competencia de otras jurisdicciones. En criterio de la Corte, este requisito se materializa si se plantea un debate de rango constitucional, el cual generalmente se da cuando se invoca la violación de un derecho fundamental, como lo es el debido proceso ${ }^{39}$.

- Se debe observar el principio de subsidiariedad de la acción de tutela. El accionante debe agotar los mecanismos idóneos de defensa judicial, pues de lo contrario, es decir, si concibe la tutela como un mecanismo alternativo -y no subsidiario - de defensa, vaciará las competencias de otras autoridades judiciales y ventilará, ante el juez de tutela, asuntos de otra jurisdicción. Sobre este particular, se ha sostenido que el recurso de anulación, por regla general, es un mecanismo idóneo de defensa judicial, pues los errores de procedimiento o in procedendo, contenidos en las causales de anulación de los laudos, contribuyen a proteger el debido proceso ${ }^{40}$. Por ende, se debe agotar el recurso de anulación para luego activar la acción de tutela, en la medida en que persista la violación a un derecho fundamental. Sin embargo, la Corte Constitucional también ha señalado que el recurso de anulación se torna inoperante si la violación a un derecho fundamental, materializada en el arbitraje, no encaja en alguna de las causales de anulación previstas en la ley, situación en la cual procede la tutela sin necesidad de formular dicho recurso ${ }^{41}$.

- Se debe cumplir el requisito de inmediatez, que implica formular la acción de tutela dentro de un plazo prudente y razonable a partir del hecho que genere la vulneración. Si se excede dicho término prudente

Véase, entre muchas otras: Corte Constitucional de Colombia. Sentencias C-590 del 2005; SU-817 del 2010 y SU-500 del 2015.

Corte Constitucional de Colombia. Sentencia SU-500 del 2015.

Corte Constitucional de Colombia. Sentencia SU-033 del 2018.

Corte Constitucional de Colombia. Sentencias SU-033 del 2018 y SU-500 del 2015. 
y razonable sin que se formule la acción, se violan principios cardinales como la seguridad jurídica y la cosa juzgada.

- Se debe demostrar que la irregularidad procesal alegada ha afectado, de manera decisiva y determinante, la decisión impugnada y los derechos fundamentales.

- $\quad$ Se deben identificar razonablemente los hechos que generan la vulneración, incluyendo la objeción oportuna que se haya formulado ante el tribunal arbitral, si ello hubiese sido posible.

- La impugnación no debe versar sobre una sentencia de tutela.

\subsection{Requisitos específicos del amparo}

Una vez despejado el análisis de procedibilidad de la tutela, se debe determinar si opera el amparo frente a la decisión arbitral. En particular, tratándose de los laudos en arbitrajes nacionales, se determina si se ha configurado o no una vía de hecho judicial. Las principales modalidades de vía de hecho judicial, aplicables al arbitraje, se sintetizan así ${ }^{42}$ :

- Vía de hecho por defecto orgánico. Opera cuando los árbitros son manifiestamente incompetentes para conocer y resolver el caso.

- Vía de hecho por defecto fáctico. Opera cuando los árbitros han incurrido en graves errores en su labor de valoración probatoria. En todo caso, “[...] es necesario que el error en la valoración probatoria haya sido determinante respecto del sentido de la decisión finalmente definida en el laudo"43

- Vía de hecho por defecto sustantivo. Opera cuando los árbitros, en su labor de interpretación o aplicación de las normas para resolver el caso concreto, incurren en graves errores $-i$. e. sustentar la decisión con normas inaplicables-.

- Vía de hecho por defecto procedimental. Opera cuando los árbitros desconocen, de manera evidente, el procedimiento aplicable al respectivo arbitraje y dicho error resulta material al desconocer las garantías fundamentales del debido proceso ${ }^{44}$. En todo caso, para que esta irregu- 
laridad constituya vía de hecho se requiere que [...] aquella tenga una incidencia directa en el sentido de la decisión adoptada, de tal forma que si no se hubiera incurrido en ella se habría llegado a una determinación diametralmente opuesta" ${ }^{\prime 4}$.

Como se puede observar, las últimas tres vías de hecho judiciales mencionadas implican que el juez de tutela, en la práctica, aborde el fondo de la decisión arbitral, incluyendo la incidencia de los respectivos errores frente a lo decidido.

Igualmente, y siendo consciente de la naturaleza y características del arbitraje, la Corte Constitucional ha señalado que

[...] si bien es posible y procedente aplicar la doctrina de las vías de hecho a los laudos arbitrales, dicha doctrina ha de aplicarse con respeto por los elementos propios de la naturaleza del arbitraje, los (sic) cual implica que su procedencia se circunscribe a hipótesis de vulneración directa de derechos fundamentales ${ }^{46}$.

\subsection{Procedencia de la tutela contra laudos en arbitrajes internacionales con sede en Colombia}

En la Sentencia T-354 del 2019, la Corte Constitucional desarrolló, por primera vez, una metodología de análisis específicamente dirigida a la tutela contra laudos proferidos en arbitrajes internacionales con sede en Colombia ${ }^{47}$.

de un laudo en un arbitraje internacional con sede en dicho país. En el caso, perteneciente a la "saga Gecelca", el Consejo de Estado interpretó que la prohibición del juez de anulación, para analizar el fondo de la decisión arbitral incluyendo las valoraciones, interpretaciones o criterios de los árbitros -artículo 107 de la Ley 1563 del 2012-, implicaba que una violación del procedimiento aplicable no requiriese una revisión de materialidad, razón por la cual la anulación del laudo procedería -como ocurrió en dicho caso- bajo un análisis preciso o literal del defecto procedimental. En particular, al sustentar la anulación del laudo, el Consejo de Estado sostuvo que "[...] el desconocimiento de la norma procesal pactada, que se concretó en negarle el derecho al recurrente de allegar un dictamen pericial y en permitirle al consorcio convocante un dictamen pericial en la etapa oral del procedimiento, es razón suficiente para decretar la nulidad del laudo solicitada en el recurso interpuesto por dicha parte, sin que resulte procedente indagar cuál fue la incidencia de esta irregularidad en la decisión adoptada en el laudo".: Consejo de Estado de Colombia. Sección Tercera. Sentencia del 27 de febrero del 2020. La sentencia T-354 del 2019, de la Corte Constitucional de Colombia, también forma parte de la "saga Gecelca". Allí, la Corte desestimó la acción de tutela al considerar que, en atención al principio de subsidiariedad de la acción de tutela, era necesario esperar el desenlace del recurso de anulación del laudo, situación que fue resuelta precisamente por el Consejo de Estado en el referido fallo del 27 de febrero del 2020.

45 Corte Constitucional de Colombia. Sentencia T-466 del 2011.

46 Corte Constitucional de Colombia. Sentencia SU-174 del 2007.

47 Una reseña de este fallo se encuentra en: Eduardo Zuleta y María Camila Rincón. “Colombia's Constitutional Court Declares That Constitutional Injunctions (Tutela) Can Be Upheld Against Awards In International Arbitration", Kluwer Arbitration Blog (Wolters Kluwer, 4 de noviembre de 2019), 
La Corte refrendó la equivalencia material entre los laudos y las sentencias judiciales. Así mismo, señaló que la procedencia estricta de la acción de tutela, aplicable al arbitraje local, se hacía extensiva al arbitraje internacional. De ahí que las consideraciones sobre el carácter excepcional de la tutela contra laudos -i. e. el principio de habilitación-, resultaran aplicables al arbitraje internacional.

Sin embargo, la Corte fue más allá al indicar que la procedencia de la tutela, en los casos internacionales, sería marcadamente excepcional o "excepcionalísima". Para ello, invocó los siguientes aspectos:

- La intervención judicial limitada que el legislador previó frente a los arbitrajes internacionales. Tal como se explicó, la Corte indicó que la Ley 1563 del 2012, en su artículo 67, ha condicionado la intervención de los jueces a aquellos aspectos expresamente señalados por dicha ley. Así, si bien es cierto que la norma legal no puede rebasar el ámbito objetivo y la supremacía normativa de la Constitución, también lo es que el legislador ha buscado, en lo posible, que los jueces estatales intervengan para lo estrictamente necesario conforme a la ley. El juez de tutela puede entonces revisar los laudos, pero teniendo en consideración la voluntad del legislador.

- La libertad de escogencia del derecho sustancial aplicable. La Corte tuvo en cuenta un principio universal del derecho arbitral, consistente en la autonomía de las partes para escoger el sistema jurídico aplicable para regir su respectivo contrato. Existen múltiples legislaciones y reglamentos arbitrales que así lo reconocen ${ }^{48}$. En el caso concreto, la Corte

http://arbitrationblog.kluwerarbitration.com/2019/11/04/colombias-constitutional-court-decla res-that-constitutional-injunctions-tutela-can-be-upheld-against-awards-in-international-arbitra tion/; y Santiago Talero Rueda. "Salient Features of the Colombian Constitutional Court's Review of Awards in International Arbitrations", Kluwer Arbitration Blog (Wolters Kluwer, 28 de noviembre de 2019), http://arbitrationblog.kluwerarbitration.com/2019/11/28/salient-features-of-the-colom bian-constitutional-courts-review-of-awards-in-international-arbitrations/

Véase, entre muchos otros, Artículo 28(1) de la Ley Modelo de Uncitral; sección 46(1) del English Arbitration Act; artículo 1511 del Código de Procedimiento Civil francés; artículo 1051 del Código de Procedimiento Civil alemán; artículo 1710 del Código Judicial de Bélgica; artículo 34(2) de la Ley 60 del 2003 de Arbitraje de España; artículo 101 de la Ley 1563 del 2012 de Colombia; artículo 28(1) de la la Ley 19971 del 2004 de Chile; y artículo 57(2) de la Ley de Arbitraje del Perú. También: artículo 21(1) del Reglamento de Arbitraje de la CCl del 2021; artículo 22(3) del Reglamento de LCIA del 2020; artículo 34(1) del Reglamento de Arbitraje de ICDR; artículo 3.29 del Reglamento de Arbitraje Comercial Internacional del Centro de Arbitraje y Conciliación de la Cámara de Comercio de Bogotá; artículo 21(1) del Reglamento de Arbitraje del Centro de Arbitraje de la Cámara de Comercio de Lima; y artículo 26(1) del Centro Internacional de Arbitraje de Madrid, entre otros. Véase, Fouchard, Gaillard y Goldman, International Commercial Arbitration (La Haya: Kluwer Law International, 1999), 785-777; Alan Redfern, Martin Hunter, Nigel Blackaby y Constantine Partasides QC, Redfern and Hunter on International Arbitration (Oxford: Oxford 
decidió que dicho derecho sustancial aplicable determinaría la metodología para saber si procede o no la tutela contra el laudo respectivo.

- La existencia de la causal de anulación, por violación del orden público internacional, prevista en la Ley 1563. Tras revisar los alcances de la noción de orden público internacional ${ }^{49}$, la Corte consideró que esta última le da a la parte interesada las herramientas para defender sus derechos fundamentales en un recurso de anulación del laudo. En otras palabras, la violación del orden público internacional de Colombia, como causal de anulación de laudos en arbitrajes internacionales, implicaría que el recurso de anulación fuera un mecanismo idóneo de defensa judicial, razón por la cual su agotamiento resultaría obligatorio en el marco del principio de subsidiariedad de la acción de tutela. De este modo, la Corte reforzó el principio de subsidiariedad de la tutela tratándose de arbitrajes internacionales.

Bajo estas premisas, la Corte creó una metodología de análisis para determinar la procedencia de la tutela contra laudos en arbitrajes internacionales, basándose en el derecho sustancial aplicable al contrato entre las partes. En particular, sostuvo que,

[...] frente a las acciones de tutela que se presenten contra laudos proferidos en Colombia con derecho sustancial extranjero, no es posible aplicar los requisitos de procedibilidad especiales propios de la acción de tutela debido a que el único parámetro de control al cual el juez constitucional puede sujetar su análisis es el orden público internacional de Colombia y, al estar la violación de este último contemplada como una causal de anulación, se hace indispensable agotar previamente dicho recurso. En este contexto, el juez únicamente puede aplicar los requisitos específicos de procedibilidad en acciones de tutela formuladas contra laudos que estén gobernados, al menos parcialmente, por la ley colombiana y, aún en esos casos, la aplicación de estos requisitos habrá de respetar al máximo los elementos característicos de tal arbitraje ${ }^{50}$.

En criterio del autor, esta llamativa consideración de la Corte significa que, tratándose de arbitrajes internacionales en los cuales el derecho sustancial aplicable

University Press, 2015), 187-189; Santiago Talero Rueda, Arbitraje comercial internacional: instituciones básicas y derecho aplicable (Bogotá: Temis, Ediciones Uniandes, 2008), 285-292; entre otros. 
sea total o parcialmente la ley colombiana, la procedencia de la tutela sigue el mismo camino del arbitraje nacional. De ahí que se apliquen las causales generales de procedibilidad de la acción y las vías de hecho como requisitos específicos del amparo. Si el derecho sustancial aplicable es extranjero -i. e. las leyes del Estado de Nueva York-, se aplican entonces las causales generales de procedibilidad de la acción, pero el amparo, como tal, queda supeditado únicamente a la violación del orden público internacional de Colombia.

\section{Cuestiones problemáticas de la jurisprudencia constitucional frente a la acción de tutela contra laudos arbitrales}

Como ya se dijo, la acción de tutela contra laudos arbitrales es una realidad en Colombia, tanto en arbitrajes locales como en los internacionales que tengan su sede en el país. De tiempo atrás, la Corte Constitucional ha sido explícita al activar los principios de supremacía normativa y de aplicación objetiva y territorial de la Constitución Política, respecto de la tutela contra los laudos arbitrales. La posibilidad de una reforma normativa afrontaría múltiples inconvenientes, incluyendo la posición de la propia Corte Constitucional sobre la improcedencia de aquellos cambios que limiten la acción de tutela.

Pese a dichas premisas, la jurisprudencia constitucional no resulta del todo pacífica y, en un momento dado, se podría replantear retomando algunos de sus elementos y dejando otros de lado.

En particular, sería viable revisar, entre otros, los siguientes aspectos: (1) la equivalencia material entre los laudos y las sentencias judiciales, con sus respectivas consecuencias; (2) la aproximación a la noción del orden público internacional; y (3) la metodología empleada en la Sentencia T-354 del 2019 para la procedencia de la tutela en arbitrajes internacionales.

\subsection{La Corte Constitucional ha equiparado los laudos a las sentencias judiciales sin aplicar su propia jurisprudencia}

La Corte ha sostenido que los laudos y las sentencias son equivalentes, para efectos de la tutela, debido a que aquellos y estas son actos jurisdiccionales emanados 
de la función de administrar justicia y que hacen tránsito a cosa juzgada. En últimas, dichas decisiones pueden vulnerar derechos fundamentales.

Con todo, también ha señalado que la equivalencia es relativa, pues al arbitraje se acude por la voluntad de las partes, plasmada en el pacto arbitral, situación que también goza de supremacía normativa según el principio constitucional de habilitación. De este modo, el principio constitucional de habilitación implica que las partes, al pactar el arbitraje, renuncian a que la justicia ordinaria estatal resuelva el fondo de sus controversias. De ahí que la Corte haya recalcado el respeto hacia las decisiones autónomas de los árbitros y la correlativa imposibilidad, por parte del juez, para pronunciarse sobre el fondo del litigio sometido a la decisión arbitral. En consonancia con lo anterior, ha sostenido que los laudos deben gozar de estabilidad jurídica ${ }^{51}$.

Estas consideraciones de la Corte Constitucional, que - se insiste- han sido claras, explícitas y reiterativas en sus sentencias, no serían afines a las respectivas consecuencias. En otras palabras, la equivalencia entre los laudos y las sentencias ha llevado a la Corte a aplicar indistintamente los mismos requisitos de procedencia de la acción de tutela, tanto para laudos como para fallos judiciales, sin atender los matices que la propia Corte ya ha planteado en sus decisiones.

Dicha situación se observa principalmente, mas no únicamente, en materia de laudos en arbitrajes nacionales y de laudos en arbitrajes internacionales en los cuales el derecho sustancial aplicable sea la ley colombiana, conforme a lo dicho en la Sentencia T-354 del 2019.

A continuación, se abordan los puntos concretos susceptibles de revisión, los cuales se desprenden del análisis de equivalencia entre los laudos y las sentencias.

51 La estrecha relación entre el principio de habilitación y la estabilidad jurídica de los laudos, ha sido reconocida por la corte al señalar lo siguiente: "La voluntad de las partes es, así, un elemento medular del sistema de arbitramento diseñado en nuestro ordenamiento jurídico, y se proyecta en la estabilidad de la decisión que adoptará el tribunal arbitral [...]". Más aún, como consecuencia del acuerdo de voluntades reflejado en el pacto arbitral, las partes aceptan por anticipado que se sujetarán a lo decidido por el tribunal de arbitramento": Corte Constitucional de Colombia. Sentencia SU-174 del 2007. Con todo, dicha estabilidad no se materializa plenamente en la práctica. Al respecto, se ha señalado, en forma estadística, cómo las tutelas contra laudos arbitrales en países como Colombia, llevan a que la situación jurídica entre las partes quede finalmente resuelta varios años después de proferidos los respectivos laudos: Juan Antonio Gaviria y Néstor Londoño, "El conflicto entre la acción de tutela colombiana y la Convención de Nueva York sobre reconocimiento y ejecución de las sentencias arbitrales extranjeras", en Reconocimiento y ejecución de sentencias arbitrales extranjeras en España y en Latinoamérica, editado por Katia Fach y Ana Mercedes López (Madrid: Tirant Lo Blanch, 2019), 319-338. 


\subsubsection{Primer elemento para revisar: algunas causales generales de procedibilidad}

La jurisprudencia de la Corte Constitucional ha señalado que las causales generales de procedibilidad o admisibilidad de la acción de tutela aplicarían a los laudos en arbitrajes nacionales, y también a los laudos en arbitrajes internacionales al margen de cuál sea el derecho sustancial aplicable al contrato entre las partes. Se trata entonces de un asunto transversal.

En particular, llaman la atención dos causales generales de procedibilidad: (1) la evidente relevancia constitucional y (2) la incidencia decisiva de la irregularidad alegada frente al sentido del laudo.

1. Evidente relevancia constitucional. Como se vio, la Corte ha asociado este requisito de procedibilidad a que la parte interesada plantee un debate de rango constitucional, en el cual identifique la violación de un derecho fundamental - i. e. el debido proceso-.

Sin embargo, el criterio de relevancia constitucional podría ser más riguroso con base en algunos aportes del derecho comparado. En efecto, según la jurisprudencia española "[...] para la admisión del recurso de amparo no es suficiente la mera lesión de un derecho fundamental o libertad pública del recurrente tutelable en amparo [...] sino que además es indispensable, en lo que ahora interesa, la especial trascendencia constitucional del recurso", lo cual ocurre, por ejemplo, ante circunstancias como (a) peticiones de amparo sustentadas en derechos fundamentales sobre los cuales el Tribunal Constitucional no ha establecido doctrina; (b) cambios sociales o normativos relevantes frente al respectivo derecho fundamental; e (c) incumplimiento, de manera general y reiterada, de la doctrina del Tribunal Constitucional, que amerite un pronunciamiento, entre otros ${ }^{52}$.

De ahí que, en atención a los aportes del derecho comparado, la identificación de un debate de rango constitucional no sea suficiente para satisfacer esta causal de admisibilidad de la acción de tutela. En otras palabras, el requisito de especial relevancia constitucional parece ir más

Tribunal Constitucional de España. Sentencia 155/2009 del 25 de junio. También: Sentencia $46 / 2020$ del 15 de junio, en la que se consideró cumplido el requisito pues el recurso de amparo denotaba la necesidad de sentar doctrina sobre el derecho fundamental vulnerado. 
allá del caso concreto, al centrarse en circunstancias exógenas como la ausencia de doctrina sobre el derecho fundamental cuya violación se invoca en la solicitud de amparo ${ }^{53}$.

2. Incidencia decisiva de la irregularidad alegada en el sentido del laudo. En su ejercicio de equiparación entre los laudos y las sentencias para efectos de la acción de tutela, la Corte Constitucional ha señalado que la irregularidad alegada por la parte interesada debió afectar decisivamente el sentido del laudo arbitral.

Esta causal o requisito general de admisibilidad de la tutela tiene dos inconvenientes en materia de arbitraje: (a) ignora los matices introducidos por la misma Corte frente a la equivalencia entre los laudos y las sentencias; y (b) confluye con algunos requisitos específicos del amparo, que se aplican frente al análisis de fondo del caso y no frente a la admisibilidad o procedibilidad del recurso o acción de tutela.

Sobre el primer punto, la Corte ha puntualizado que la acción de tutela debe proceder en forma excepcional en materia de arbitraje local, y en forma marcadamente excepcional o "excepcionalísima" respecto del arbitraje internacional. En cualquiera de los casos, la propia Corte ha recalcado, en múltiples fallos, la importancia del principio constitucional de la habilitación, incluyendo la imposibilidad del juez para pronunciarse sobre el fondo del asunto y la correlativa necesidad de proteger la estabilidad jurídica del laudo. En este orden de ideas, la sola exigencia de acreditar que la irregularidad alegada haya afectado decisivamente el sentido del laudo, pone al juez de tutela en la necesidad de revisar, quiérase o no, dicha situación, y, al hacerlo, el riesgo de invasión al principio constitucional de habilitación aumenta considerablemente. En otras palabras, al determinar si la irregularidad planteada por el recurrente ha incidido decisivamente o no frente al sentido del laudo arbitral, el juez de tutela puede terminar convertido en juez de instancia. en la Sentencia SU-556 del 2016 de la Corte Constitucional de Colombia. En su salvamento de voto, y al abordar este requisito, el magistrado Alejandro Linares sostuvo que "[...] la decisión terminó resolviendo un asunto netamente comercial, en el que el problema jurídico consistía en la identificación de la intención de las partes de un contrato de seguros y en la aplicación de la regla de interpretación favorable al acreedor o en contra de quien redactó la cláusula confusa. Es decir, el asunto considerado como de evidente relevancia constitucional consistía en saber si la norma aplicable era el inciso primero o el inciso segundo del artículo 1624 del Código Civil o los artículos 1620 y 1622 del mismo Código, así como el artículo 1058 del Código de Comercio...". 
Ello, a su turno, riñe con el principio constitucional de habilitación y con la estabilidad del laudo arbitral, asuntos estos que la Corte ha planteado precisamente como límites o matices frente a la acción de tutela contra decisiones arbitrales.

Sobre el segundo punto, ocurre que las vías de hecho judiciales, extendidas por la Corte al campo del arbitraje, exigen en general que el juez de tutela determine si el error incurrido por los árbitros ha sido determinante o no frente al sentido del laudo. En este punto, confluye entonces el requisito general de procedibilidad que se analiza, esto es, que la irregularidad alegada haya incidido decisivamente frente al sentido del laudo, con algunos requisitos específicos del amparo como lo son las vías de hecho por defecto fáctico, sustantivo y procedimental ${ }^{54}$. Dicha situación, incluyendo su redundancia, se debería revisar.

\subsubsection{Segundo elemento para revisar: las vías de hecho judiciales}

La jurisprudencia de la Corte Constitucional ha señalado que las vías de hecho judiciales - por defecto orgánico, fáctico, sustantivo y procedimental-aplicarían a los laudos en arbitrajes nacionales, y también a los laudos en arbitrajes internacionales cuando el derecho sustancial aplicable sea total o parcialmente la ley colombiana.

Este es el espectro actual o lex lata del amparo constitucional frente a dichos arbitrajes. Tal como se indicó en la sección anterior, las vías de hecho mencionadas exigen, en general, que el juez de tutela determine si el error incurrido por los árbitros ha sido determinante o no frente al sentido del laudo. En efecto, la Corte ha señalado expresamente que las vías de hecho por defecto fáctico y procedimental se configuran cuando se demuestra que la irregularidad ha sido decisiva frente al sentido del laudo arbitral. Respecto de la vía de hecho por defecto sustantivo, la jurisprudencia no ha sido igualmente explícita en exigir prueba de su incidencia frente al sentido de la decisión. No obstante, es evidente que allí se sigue este mismo derrotero ${ }^{55}$. Así, las situaciones típicas de la vía de hecho por

La vía de hecho por defecto orgánico no sería redundante frente a la causal general de procedibilidad de la tutela que se analiza, en la medida en que la manifiesta incompetencia de los árbitros, en un caso concreto, es un asunto que solo mira si estos tenían o no la potestad o autoridad para conocer y resolver el litigio, al margen de cuál pudiera ser el sentido de su decisión.

55 De hecho, en ocasiones la Corte Constitucional ha abordado el defecto sustantivo en conjunto con el fáctico, el cual exige establecer la incidencia decisiva, de la irregularidad respectiva, en el sentido del laudo. E incluso la propia Corte ha sostenido que el defecto sustantivo lleva al juez de tutela "[...] a controlar la razonabilidad del análisis contenido en el laudo". Este control, por ejemplo, ha llevado a la corte a señalar que "[...] la decisión arbitral cuestionada presenta entonces notorios defectos 
defecto sustantivo, como son la indebida interpretación o aplicación de las normas jurídicas, exigen del juez, en la práctica, una rigurosa revisión de la ratio decidendi del laudo.

De este modo, todo indicaría que la aplicación, por parte de la Corte, de las vías de hecho judiciales a los laudos arbitrales, deja de lado las diferencias fundamentales entre el arbitraje y la justicia ordinaria. Si una sentencia judicial está sujeta a un recurso de apelación, habrá un juez que revise la decisión de fondo tomada por otro juez. En un escenario general como este, es perfectamente natural que se construyan doctrinas sobre vías de hecho judiciales con los alcances que les ha dado la Corte Constitucional. Un sistema judicial, en términos generales, acoge con alguna normalidad el hecho de que un juez revise si otro, por ejemplo, ha incurrido en un error protuberante en la valoración de las pruebas. Pero en el arbitraje el asunto es muy distinto, según los lineamientos que la propia Corte ha identificado y reiterado en múltiples sentencias.

En realidad, el quid del asunto está en la propia Constitución Política. Se trata del principio constitucional de habilitación, que también goza de supremacía normativa. La norma fundamental colombiana, en forma expresa y directa, tutela el derecho de las partes a acudir al arbitraje, esto es, a renunciar a que el sistema estatal de administración de justicia resuelva el fondo de sus controversias. De ahí que la equivalencia material, entre laudos y sentencias, para efectos de la acción de tutela, tenga el "pecado original" de suponer que las vías de hecho judiciales se pueden trasplantar al arbitraje sin atender su naturaleza reconocida constitucionalmente. Desde otra perspectiva, la Corte Constitucional ha advertido que el principio de habilitación marca una diferencia entre los laudos y las sentencias de los jueces, razón por la cual la procedencia de la tutela es excepcional o restringida frente a los laudos arbitrales. Pero este planteamiento, que es sumamente claro en los fallos de la Corte, se desatiende en la práctica cuando se prevén, como requisitos específicos del amparo, vías de hecho diseñadas para el sistema estatal

en su razonamiento interpretativo sobre el contenido del contrato, toda vez que sin motivación escoge los segmentos del negocio que considera relevantes, en lugar de hacer una interpretación integral de sus elementos; omite sin justificación suficiente darles a otros aspectos, que sí describe, el valor de contribuciones al esclarecimiento del sentido de lo acordado; sustrae del contexto histórico y jurídico un documento contractual esencial, como es el formulario de solicitud de póliza de indemnización profesional, en la parte decisiva del razonamiento para la justificación de la duda; y extrae conclusiones interpretativas sin argumentos, que le agregan dosis innecesarias de imprecisión al problema". Y así ha concluido que se generan dos defectos sustantivos: "[...] defecto sustantivo originado en la manifiesta irrazonabilidad de su interpretación de elementos decisivos del negocio jurídico; un defecto sustantivo ocasionado por privar irrazonablemente de sus efectos a las normas pertinentes de la Constitución en la interpretación del negocio jurídico, y por sus visibles extravíos en la aplicación de una regulación y una conceptualización inatinente al contrato". Todo esto ocurrió en: Corte Constitucional de Colombia. Sentencia SU-556 del 2016. 
de administración de justicia y que llevan al juez de tutela a invadir el núcleo del principio constitucional de la habilitación ${ }^{56}$.

La vía de hecho por defecto orgánico no tiene el mismo inconveniente, pues para su configuración no se requiere analizar si el defecto o irregularidad incide o no en el sentido del laudo arbitral. En otros términos, este defecto opera ante el hecho de que los árbitros asuman competencia en forma manifiestamente equivocada -i. e. en un caso de homicidio-, al margen de cuál sea el laudo o decisión de fondo.

Por supuesto, la posibilidad de invocar las vías de hecho judiciales — defecto orgánico, fáctico, sustantivo o procedimental- en las acciones de tutela contra laudos, es el estado actual de la ley - lex lata- y no la ley como debería ser en el futuro -lex ferenda-. De ahí que los litigantes, por lo pronto, puedan invocar libremente la configuración de las respectivas vías de hecho, en relación con los laudos y en defensa de los intereses de los clientes. Es natural que así sea mientras no se replantee la jurisprudencia vigente.

\subsection{La noción de orden público internacional afronta un riesgo de ensanchamiento}

Como se vio, en la Sentencia T-354 del 2019 la Corte Constitucional invocó la noción de orden público internacional para dos propósitos distintos. Por una parte, para afianzar el principio de subsidiariedad de la acción de tutela, al señalar que la violación del orden público internacional, como causal de anulación de laudos en arbitrajes internacionales, implicaba que el recurso de anulación fuera un mecanismo idóneo de defensa judicial y de obligatorio agotamiento antes de formular la acción de tutela. Y, por otra parte, para servir como requisito específico del amparo contra laudos, en aquellos arbitrajes internacionales en los cuales el derecho sustancial aplicable fuera extranjero.

En su sentencia, la Corte analizó los alcances de la noción de orden público internacional, para lo cual retomó los lineamientos que, sobre dicho particular, ha trazado la Corte Suprema de Justicia al resolver recursos de anulación de laudos

56 No en vano, la Corte Suprema de Justicia de Argentina, de tiempo atrás, sostuvo que "[...] no es posible negar la revisibilidad de los laudos arbitrales $y$, a la vez, afirmar que puede revisarse su arbitrariedad sin caer en flagrante contradicción": Corte Suprema de Justicia de Argentina. Sentencia del caso Meller Comunicaciones S. A. U. T. E. v Empresa Nacional de Telecomunicaciones, 5 de noviembre del 2002, citada por: Julio César Rivera refiriéndose a los votos concurrentes de los jueces Nazareno y Boggiano. "La revisión judicial del laudo arbitral en Argentina: aspectos constitucionales". Revista Arbitraje PUCP n. ${ }^{\circ}$ (2014): 175-181. 
en arbitrajes internacionales o al decidir sobre solicitudes de reconocimiento de laudos extranjeros en Colombia ${ }^{57}$.

\subsubsection{La noción de orden público internacional \\ y su tratamiento por parte de la Corte Suprema de Justicia}

La noción de orden público, en términos generales, hace referencia al carácter inderogable de una norma ${ }^{58}$. Dicho carácter inderogable suele reflejar un deber de abstención en cabeza de las partes, consistente en no poder pactar en contrario de lo que la norma señala.

Tradicionalmente, la norma de orden público ha correspondido al denominado "orden público de dirección" — leyes de policía—, es decir, a las "[...] reglas y principios fundamentales sobre los cuales reposa la estructura estatal, ya sean de contenido político, social o económico [...] que protegen intereses de la comunidad toda..." 59 , o al denominado "orden público de protección", es decir, a las

[...] normas que buscan salvaguardar intereses particulares, vale decir, de ciertos empresarios, gremios o contratantes que tienen una posición débil de negociación frente a la otra parte que ostenta una posición de dominio para efectos del establecimiento de los términos y condiciones que han de gobernar una relación negocial ${ }^{60}$.

Existe una tercera categoría, conocida como norma de "orden público internacional" ${ }^{\prime \prime}$, que no es novedosa en el derecho de los negocios internacionales ${ }^{62}$. Sin embargo, su definición es esencialmente difusa. A continuación, se abordará

La violación del orden público internacional constituye causal para denegar el reconocimiento y ejecución de laudos extranjeros en Colombia, a la luz del artículo V.2.b) de la Convención de Nueva York de 1958 sobre reconocimiento y ejecución de sentencias arbitrales extranjeras, la cual fue incorporada al ordenamiento jurídico colombiano mediante la Ley 39 de 1990.

Jorge Suescún, Derecho privado: estudios de derecho civil y comercial contemporáneo, t. II (Bogotá: Legis, Ediciones Uniandes, 2003), 530; Santiago Talero Rueda, "La agencia comercial y los sistemas de distribución en el arbitraje internacional", Revista de Derecho Privado n. ${ }^{\circ} 44$ (2010): 11-21. Formation 3 Edition (París: Librairie Genérale de Droit et Jurisprudence [LGDJ], 1993), 778. Suescún, ibid., 528-529.

Carlos Holguín Holguín, “La noción de orden público en el derecho internacional privado”, IDEA-El derecho de los negocios internacionales (Bogotá: Universidad Externado de Colombia, 1991), 406418. Este autor señala como términos sinónimos del orden público internacional, el "orden público absoluto" o la "cláusula de reserva".

62 La construcción de la noción de orden público, en sus distintas modalidades e incluyendo la del orden público internacional de un Estado, se encuentra en: Santiago Talero Rueda, Arbitraje comercial internacional: instituciones básicas y derecho aplicable (Bogotá: Temis, Ediciones Uniandes, 2008), 435-445. 
la figura en el arbitraje internacional. Luego se sintetizará su tratamiento en la jurisprudencia de la Corte Suprema de Justicia, dado que esta ha sido consultada y acogida por la Corte Constitucional.

\subsubsection{El orden público internacional en el arbitraje internacional}

La noción de orden público internacional ha sido entendida como el conjunto de

[...] estándares fundamentales de la comunidad internacional, incluyendo los principios del intercambio comercial y otros criterios de carácter humanitario, los cuales se desarrollan a partir de los estándares comunes de las políticas nacionales y de los conceptos fundamentales contenidos en las convenciones internacionales y en otros instrumentos internacionales ${ }^{63}$.

También se ha sostenido que el

[...] orden público internacional de cada Estado incluye: (i) principios fundamentales, relativos a la justicia o moralidad, que el Estado desee proteger aun cuando no lo atañan directamente; (ii) normas diseñadas para servir a los intereses políticos, sociales o económicos fundamentales del Estado, siendo estas conocidas como "lois de pólice" o "normas de orden público" y (iii) el deber del Estado de respetar sus obligaciones con otros Estados u organizaciones internacionales ${ }^{64}$.

Un tribunal de Estados Unidos, en un caso emblemático, definió la noción como el conjunto de "[...] conceptos más básicos de moralidad y justicia del Estado"65. La jurisprudencia suiza, a su turno, ha señalado que la noción de orden público internacional se configura en la medida en que se violen principios jurídicos fundamentales, de manera que la violación no sea conciliable con el orden jurídico y con el sistema de valores imperante ${ }^{66}$. La jurisprudencia española, por su parte, ha señalado que la causal de orden público es aplicable cuando el laudo viola los derechos

63 Julian Lew, “Determination of arbitrators' jurisdiction and the public policy limitations on that jurisdiction", cap. 7, Contemporary Problems in International Arbitration (Londres: CCLS, 1986), 83 (traducción del autor).

64 Pierre Mayer \& Audley Sheppard, “Informe final de la Asociación de Derecho Internacional acerca del orden público como una prohibición para la ejecución de los laudos arbitrales", Revista Internacional de Arbitraje vol. I (2004): 220.

65 Parson \& Whittemore Overseas Co. Inc. v. Societé Générale de I'Industrie du Papier Rakta and Bank of America 508 F.2d 969 (2 Cir., 1974).

66 Juan Pablo Cárdenas. "Las causales para negar el reconocimiento de un laudo que pueden ser declaradas de oficio”, Congreso Internacional de Arbitraje (Bogotá, abril del 2005), citando un fallo proferido el 30 de diciembre de 1994. 
y garantías fundamentales previstos en la Constitución, especialmente cuando una de las partes se encuentra en situación de indefensión ${ }^{67}$. En otro caso, una corte de apelaciones de Hong Kong sostuvo que el orden público internacional se violaba si el respectivo laudo ofendiere sustancialmente las nociones de justicia de la respectiva jurisdicción ${ }^{68}$. La noción de orden público internacional cobija aspectos sustanciales y procesales ${ }^{69}$, dado que su alcance, como tal, se refiere a las nociones básicas de moralidad, justicia y estabilidad de un Estado, sin distinguir entre aquellas que tienen una naturaleza procesal y las que tienen una naturaleza sustancial.

El orden público internacional se activa entonces en presencia de situaciones que comprometan los principios más básicos o elementales de moralidad, justicia o estabilidad de un Estado. Cada Estado tiene un orden público internacional, el cual se funda en sus principios fundamentales y puede tener carácter dinámico en la medida en que dichos principios se vayan ajustando a las nuevas realidades sociales o económicas del respectivo país.

En todo caso, el orden público internacional corresponde, en esencia, a una noción eminentemente restrictiva. Las autoridades judiciales no tienen "carta blanca" para ensanchar dicho concepto, pues una norma de esta naturaleza, además de su carácter inderogable, debe tener importancia fundamental para el Estado que la invoca ${ }^{70}$. De este modo, si un Estado, como Colombia, reconoce el arbitraje internacional, también se obliga a adoptar un alcance restrictivo de la noción de orden público.

El orden público internacional sirve entonces como mecanismo restrictivo y excepcional para el control judicial de los laudos arbitrales. Ello puede suceder cuando las cortes realizan el control de validez del laudo -i. e. en el recurso de anulación- ${ }^{71} \mathrm{o}$ al ejercer el control de eficacia territorial de aquel -i. e. en el trámite de reconocimiento del laudo extranjero- ${ }^{72}$. La acción de tutela, a su turno, compromete la validez del laudo, tal como ocurre cuando se acude al recurso de anulación.

Cárdenas, ibid., citando la sentencia del 15 de abril de 1986, proferida por el Tribunal Constitucional de España.

Hebei Import and Export Corporation -v- Polytek Engineering Co. Ltd [1999] 2 HKC 205.

Audley Sheppard. "Public policy and the enforcement of arbitral awards: Should there be a global standard?", Transnational Dispute Management, vol. 1 (2004): 1; Fouchard, Gaillard \& Goldman, ibid., 957.

De hecho, la Comisión Redactora de la Convención de Nueva York manifestó expresamente que la noción de orden público debía ser restrictiva y excepcional: Reporte de la Comisión para la Ejecución de Laudos Arbitrales Internacionales. Documento ONU E/2704 y E/AC.42/4/Rev.1, del 28 de marzo de 1955.

Véase, por ejemplo, artículo 108(2)(b) de la Ley 1563 del 2012 de Colombia.

Véase, por ejemplo, artículo V.2.b) de la Convención de Nueva York. 
Como se ha visto, la violación del orden público internacional de Colombia aplica como causal para la anulación del laudo en arbitrajes internacionales con sede en el país, o como causal para denegar el reconocimiento del laudo extranjero en Colombia. En el marco de la acción de tutela, la Corte Constitucional, en su Sentencia T-354 del 2019, ha señalado que dicha noción se aplica si se acude al mecanismo de amparo constitucional tras agotarse el recurso de anulación, siempre que el derecho sustancial aplicable sea extranjero.

La Ley 1563 del 2012, en su sección tercera, ha adoptado los lineamientos de la Ley Modelo de Uncitral sobre Arbitraje Comercial Internacional, con algunos ajustes. En este contexto, el artículo 108 consagra la violación del orden público internacional de Colombia como causal de anulación de laudos, mientras que el artículo 107 señala expresamente que el juez competente para la anulación, es decir, la Corte Suprema de Justicia o el Consejo de Estado — según sea el caso- - ${ }^{73 ~ "[. . .] ~ n o ~}$ se pronunciará sobre el fondo de la controversia ni calificará los criterios, valoraciones probatorias, motivaciones o interpretaciones expuestas por el tribunal arbitral".

En tal sentido, también es pertinente anotar que la Ley 1563, en su artículo 64, incorpora el artículo 5 de la Ley Modelo de Uncitral, el cual señala expresamente que en "[...] la interpretación del arbitraje internacional habrán de tenerse en cuenta su carácter internacional y la necesidad de promover la uniformidad de su aplicación y la observancia de la buena fe". Esto significa, en términos sencillos, que en los arbitrajes internacionales los jueces deben analizar las normas bajo estándares del derecho comparado, para lo cual es pertinente revisar aportes doctrinales y jurisprudenciales que guíen u orienten la aplicación de dichas normas ${ }^{74}$.

Sobre el particular, el Compendio Uncitral del 2012 sobre la Ley Modelo de Arbitraje Comercial Internacional ofrece algunas pautas pertinentes frente al control de validez del laudo a la luz del orden público internacional. En efecto, se ha sostenido que la anulación de laudos, en el arbitraje internacional, no implica una revisión de los méritos del caso, situación que se corrobora en el artículo 107 de la Ley 1563 del $2012^{75}$. También se precisa que, tanto en los trámites de anulación como en los de reconocimiento de laudos, los jueces pueden mantener firmes las decisiones arbitrales aun si se configura alguna causal de anulación o de denegación

73 Artículo 68 de la Ley 1563 del 2012 de Colombia.

74 Esta circunstancia ha sido reconocida por la jurisprudencia nacional. Véase, por ejemplo, Corte Suprema de Justicia de Colombia. Sala de Casación Civil. Sentencia del 12 de julio del 2017; y Consejo de Estado de Colombia. Sección Tercera. Sentencia del 27 de febrero del 2020; entre otros. 
de reconocimiento ${ }^{76}$. Ello es así pues las normas pertinentes señalan que el juez "podrá anular" o "podrá denegar el reconocimiento", según sea el caso. La discrecionalidad opera entonces dependiendo de si la respectiva violación reviste o no cierta materialidad en el caso concreto. Así, frente a la causal de violación del orden público, se ha señalado que esta es de interpretación restrictiva y de aplicación discrecional ${ }^{77}$. Con todo, se admite que el orden público internacional tiene carácter procesal y sustantivo, lo cual, en un momento dado, puede implicar una revisión de los méritos del laudo, pero siempre de forma restrictiva, excepcional y limitada ${ }^{78}$.

\subsubsection{El orden público internacional según la jurisprudencia de la Corte Suprema de Justicia colombiana: desarrollo concreto}

La Corte Suprema de Justicia, en cada uno de los casos en que se ha pronunciado sobre el orden público internacional, ha resaltado su carácter eminentemente restrictivo, lo cual la ha llevado a respaldar los laudos arbitrales en forma consistente.

Esta labor de la Corte, que viene de tiempo atrás, ha registrado varios desarrollos en la última década, los cuales se pueden sintetizar así:

- Se ha resaltado el carácter restrictivo y dinámico del orden público internacional ${ }^{79}$.

- Se ha puntualizado que dicha noción hace referencia a los principios fundamentales del ordenamiento jurídico colombiano, incluyendo las nociones más básicas de moralidad y justicia del Estado ${ }^{80}$.

- Se ha sostenido que la noción abarca, entre otros, el principio de la buena fe, la prohibición del abuso del derecho, la imparcialidad de los

Compendio Uncitral, 141, citando jurisprudencia canadiense: The United Mexican States v. Metalclad Corporation. Corte Suprema de British Columbia. Sentencia del 2 de mayo del 2001.

77 Compendio Uncitral, 160, citando múltiples fallos de países como Alemania, España y Canadá, entre otros.

78 Compendio Uncitral, 161-163. Esta posibilidad plantea dificultades bajo el régimen jurídico colombiano, especialmente respecto del control judicial de validez del laudo. Al respecto, existe norma expresa —el artículo 107 de la Ley 1563 del 2012- que restringe expresamente la posibilidad del juez para pronunciarse sobre el fondo del litigio, situación que encuentra respaldo en la norma constitucional, de rango superior, que consagra el principio de habilitación —artículo 116 de la Constitución Política-. En materia de reconocimiento de laudos extranjeros no existe norma expresa en el mismo sentido, pero la Corte Suprema de Justicia de Colombia ha señalado que en el trámite de reconocimiento de laudos extranjeros tampoco se debe reexaminar la relación sustancial. Véase, por ejemplo: Corte Suprema de Justicia de Colombia. Sala de Casación Civil. Sentencia del 12 de julio del 2017. de julio del 2011; y 24 de junio del 2016, entre otras. 
árbitros y el debido proceso ${ }^{81}$. En dicho sentido, se ha retomado la Resolución 2 del 2002, de la Asociación de Derecho Internacional, en la cual se han incluido los ejemplos anteriores, y otros como el principio de pacta sunt servanda y la prohibición de la esclavitud, entre otros.

- Conforme a dicha resolución, se ha reconocido que el orden público internacional puede ser procesal o sustantivo. Así, por ejemplo, la buena fe y la prohibición del abuso del derecho forman parte del orden público internacional sustantivo, mientras que la imparcialidad de los árbitros y el debido proceso forman parte del orden público internacional procesal, lo cual incluye el derecho de defensa y la igualdad de las partes.

- Igualmente, se ha dicho que la protección de los derechos fundamentales también forma parte del orden público internacional de Colombia ${ }^{82}$.

- Se han incluido los bienes jurídicos tutelados por el derecho penal en la referida noción ${ }^{83}$.

- También se han incluido el orden social del Estado y las libertades públicas ${ }^{84}$.

- Así mismo, y tratándose de categorías generales de normas de orden público, se ha asociado la noción de orden público de dirección al orden público internacional, en contraposición con el orden público de protección ${ }^{85}$.

- $\quad$ Finalmente, se ha sugerido que el orden público internacional no se compromete o afecta cuando la relación contractual involucra a particulares, en contraposición con los contratos estatales ${ }^{86}$.

Corte Suprema de Justicia de Colombia. Sala de Casación Civil. Sentencias del 27 de julio del 2011; 24 de junio del 2016; 12 de julio del 2017; 19 de diciembre del 2018; y 15 de enero del 2019, entre otras.

Véase, por ejemplo, Corte Suprema de Justicia de Colombia. Sala de Casación Civil. Sentencias del 7 de septiembre del 2016; 12 de julio del 2017; y 15 de enero del 2019; entre otras. Véase, por ejemplo, Corte Suprema de Justicia de Colombia. Sala de Casación Civil. Sentencias del 7 de septiembre del 2016; y 12 de julio del 2017; entre otras.

Véase, por ejemplo, Corte Suprema de Justicia de Colombia. Sala de Casación Civil. Sentencia del 19 de diciembre del 2018.

Esto ocurrió a propósito de un caso de agencia comercial, en el cual las partes habían pactado arbitraje internacional y su contrato, que se ejecutaría en Colombia, se regía por una ley extranjera. Véase, Corte Suprema de Justicia de Colombia. Sala de Casación Civil. Sentencia del 24 de junio del 2016. También, sobre el mismo tema, Santiago Talero Rueda, "La agencia comercial y los sistemas de distribución en el arbitraje internacional”, Revista de Derecho Privado n. ${ }^{\circ} 44$ (2010): 11-21.

Véase, por ejemplo, Corte Suprema de Justicia de Colombia. Sala de Casación Civil. Sentencias del 27 de julio del 2011; 24 de junio del 2016; y 19 de diciembre del 2018, entre otras. Dicha interpretación es discutible, pues el orden público internacional puede verse comprometido en una relación entre particulares. 


\subsubsection{Tercer elemento para revisar: la posible aplicación acumulativa del orden público internacional de Colombia}

Por razón de sus competencias, la Corte Suprema de Justicia ha abanderado las decisiones sobre el denominado orden público internacional de Colombia. Como ya se dijo, la Corte ha abordado dicha noción bajo múltiples perspectivas, pero el resultado, en cada caso, ha sido respaldar la firmeza de los laudos.

Sin embargo, si bien es cierto que la Corte ha puntualizado el carácter restrictivo del orden público internacional colombiano, también lo es que, al indicar los ejemplos y modalidades de dicha noción, ha abierto la posibilidad para que esta se ensanche en el futuro. En otras palabras, una cosa es señalar, en cada caso, unos ejemplos de orden público internacional y así respaldar la validez o eficacia de los laudos, y otra diferente es compilar los distintos ejemplos de orden público internacional indicados por la Corte Suprema en cada caso concreto, como se hizo en la sección anterior. La razón de la distinción es sutil pero real: indicar unos ejemplos de orden público internacional, en un determinado caso, puede no afectar la firmeza del respectivo laudo, pero acumular los ejemplos de los distintos casos sí puede llegar a afectar la firmeza de los laudos en un futuro ante el riesgo de que el "contenido acumulado" se aplique para la resolución de un determinado caso.

En la Sentencia T-354 del 2019, y al retomar los distintos pronunciamientos de la Corte Suprema, la Corte Constitucional hizo precisamente un ejercicio de compilación de los principales ejemplos o modalidades de orden público internacional identificados por la Corte Suprema en sus distintas decisiones. E, incluso, hacia el final de su fallo, advirtió que la noción de orden público internacional “[...] permite que en sede de anulación se analicen defectos que desbordan quebrantamientos in procedendo...".

En la referida sentencia, la Corte Constitucional señaló que la violación del orden público internacional operaría como requisito específico del amparo, cuando la parte interesada agotara sin éxito el recurso de anulación en un caso en el cual el derecho sustancial fuera extranjero. Y aquí, de nuevo, puede ocurrir que se deje de lado la propia jurisprudencia de la Corte cuando esta recalca la necesidad de respetar el principio constitucional de habilitación y la imposibilidad de pronunciarse sobre el fondo del litigio.

En realidad, la acción de tutela y el recurso de anulación cuestionan la validez del laudo arbitral. La interpretación del arbitraje, bajo estándares internacionales, apunta hacia la ausencia de revisión sustancial del laudo en el control judicial de validez. Y en Colombia, por lo demás, una norma de rango legal así lo reconoce 
expresamente -artículo 107 de la Ley 1563 del 2012-, mientras que un principio de rango constitucional así lo reconfirma —el principio de habilitación previsto en el artículo 116 de la Constitución Política-.

En este orden de ideas, si la Corte Constitucional mantuviera la posibilidad de amparar ciertos laudos según la noción del orden público internacional, quizás lo más razonable sería que lo hiciera armonizando el estándar internacional aplicable —no revisión sustancial del laudo- con el marco legal y constitucional aplicable -respeto por el principio de habilitación-. De este modo, la noción de orden público se podría acotar aún más, al menos en lo que atañe al control de validez de los laudos.

\subsection{El derecho sustancial aplicable no justifica la distinción entre la procedencia de la tutela en arbitrajes locales e internacionales}

En términos generales, la Sentencia T-354 del 2019 señala que si el contrato entre las partes se rige total o parcialmente por el derecho colombiano, entonces la acción de tutela contra el laudo arbitral procede según el régimen habitual: configuración de las causales generales de procedibilidad y ocurrencia de al menos un requisito específico del amparo — vía de hecho por defecto orgánico, fáctico, sustantivo o procedimental-. Esto aplica para los laudos en arbitrajes locales y para aquellos de arbitrajes internacionales con derecho sustancial total o parcialmente colombiano. Contrario sensu, si el contrato entre las partes se rige por un derecho extranjero, entonces la acción de tutela procede bajo una nueva metodología: configuración de las causales generales de procedibilidad y violación del orden público internacional de Colombia, sea éste procesal o sustantivo.

En realidad, el fallo no indica por qué la Corte ideó esta metodología distinta, la cual no resultaría convincente. Así, por ejemplo, en un arbitraje internacional con sede en Colombia puede ocurrir (1) que el caso se haya resuelto bajo un derecho extranjero, y (2) que los árbitros hayan incurrido en una vía de hecho por defecto orgánico al no tener competencia para conocer y resolver el litigio. Bajo la metodología creada por la Corte, la parte interesada no podría invocar, al menos directamente, una vía de hecho, sino que tendría que invocar la violación del orden público internacional colombiano al formular la acción de tutela. Contrario sensu, en un arbitraje internacional con sede en Colombia puede ocurrir (1) que el caso se haya resuelto bajo el derecho colombiano, y (2) que los árbitros hayan violado el orden público internacional. Bajo la metodología mencionada, la parte interesada sí podría invocar la violación del orden público internacional como causal de 
anulación del laudo, pero en el momento de formular la acción de tutela tendría que alegar la ocurrencia de alguna vía de hecho, pese a que la noción de orden público internacional cobija la protección de los derechos fundamentales.

\section{Hacia una propuesta de solución}

Con alguna frecuencia ocurre que los análisis jurídicos se hacen aisladamente, es decir, cotejando una determinada situación a la luz de una disciplina específica del derecho, sin atender la incidencia o implicación que dicha situación pueda tener en otras disciplinas jurídicas o en el contexto empresarial o comercial en que la situación se desarrolla.

Este ha sido el caso de la acción de tutela contra laudos arbitrales. Quienes ejercemos la práctica arbitral a veces pretendemos que el juez constitucional acoja incondicionalmente los postulados del derecho arbitral. Y el juez constitucional, a su vez, opone razones de rango superior que desconocen la naturaleza del arbitraje y que incluso contradicen su propia jurisprudencia.

Existe una posible solución. La Corte Constitucional de Colombia ha sido clara al señalar que la acción de tutela procede contra laudos en los arbitrajes locales e internacionales con sede en el país. Pero su propia jurisprudencia, que a veces se deja de lado, ofrece soluciones eficaces para dotar a los laudos de su necesario carácter definitivo y de su correlativa estabilidad jurídica.

A continuación, se propone una aproximación distinta, incluyendo los ajustes esbozados a lo largo de este artículo:

- La aproximación que se propone parte de la premisa según la cual, la solución a la procedencia de la tutela contra laudos arbitrales no es normativa sino jurisprudencial.

- $\quad$ El eje de la propuesta es el reconocimiento real y efectivo del principio constitucional de la habilitación —artículo 116 de la Constitución Política-. La autonomía privada de las partes, consistente en renunciar a que la justicia ordinaria resuelva el fondo de sus controversias, merece la tutela judicial efectiva por parte del juez constituciona ${ }^{87}$. No en vano, 
el principio de habilitación tiene en Colombia rango constitucional y, por ende, también goza de supremacía normativa ${ }^{88}$.

- Dicho reconocimiento implica replantear la equivalencia material entre los laudos y las sentencias judiciales, conforme a la propia jurisprudencia de la Corte Constitucional.

- En efecto, se propone ajustar las causales generales de procedibilidad o admisibilidad de la tutela. Por una parte, el requisito de especial relevancia constitucional se puede hacer más riguroso, según los aportes del derecho comparado analizados atrás. Por otra, no tendría sentido insistir en que se acredite que la irregularidad alegada haya incidido decisivamente en el sentido del laudo, pues ello reñiría con el principio de habilitación y con las demás limitaciones o matices señalados por la Corte frente a la procedencia de la tutela, como se explicó atrás.

- En cuanto a los requisitos específicos del amparo, se propone eliminar las vías de hecho por defecto fáctico, sustantivo y procedimental, en la medida en que estas invaden el núcleo del principio constitucional de habilitación al exigir la prueba de su incidencia determinante o decisiva en el sentido del laudo arbitral.

- La vía de hecho por defecto orgánico quedaría entonces como único requisito específico del amparo, respecto de los laudos proferidos en arbitrajes locales. En tal sentido, sería necesario, en todos los casos, agotar previamente el recurso de anulación del laudo, puesto que la falta de competencia del tribunal arbitral constituye causal de anulación en estos $\operatorname{casos}^{89}$.

- En relación con los arbitrajes internacionales con sede en Colombia, la procedencia de la tutela nada tendría que ver con el derecho sustancial aplicable en el caso.

- En todos los casos, sin importar cuál sea el derecho sustancial aplicable, la violación del orden público internacional es una causal de anulación de los laudos, que cobija la protección de derechos fundamentales.

Desde otra perspectiva, el derecho constitucional contemporáneo reconoce un principio de unidad constitucional, según el cual cada previsión -i. e. el principio de habilitación previsto en el artículo 116 de la Constitución - debe concebirse como parte de "[...] un texto armónico y coherente, que como tal, debe ser interpretado de manera sistemática, teniendo en cuenta, además, los propósitos y objetivos perseguidos por el constituyente": Corte Constitucional de Colombia. Sentencia C-535 del 2012. A la fecha, dicho principio de habilitación ha sido considerado por la corte, pero desatendido al momento de abordar la procedencia de la acción de tutela contra laudos. 
Por ende, y atendiendo la jurisprudencia de la Corte Constitucional, la parte interesada tendría que agotar previamente el recurso de anulación, antes de formular la acción de tutela.

- $\quad$ En este sentido, pueden ocurrir dos situaciones: que las partes hayan renunciado al recurso de anulación del laudo o que no lo hayan hecho ${ }^{90}$. La Corte Constitucional ha dicho que

[...] la acción de tutela se puede plantear en dos escenarios, dependiendo de si es preciso, o no, el agotamiento del recurso de anulación. Esta situación determina que la aproximación del juez de tutela, en uno y otro caso, sea distinta. Si bien se parte siempre del respeto por el margen de decisión autónoma de los árbitros que no debe ser invadido por el juez de amparo, a quien no le corresponde pronunciarse sobre el fondo del asunto sometido a arbitramento, también es cierto que en los casos en que no resulta exigible agotar el recurso de anulación, la acción de amparo hace un primer acercamiento al laudo arbitral, y en este sentido la valoración sobre la violación directa de derechos fundamentales habrá de ser más estricta. Mientras que en los casos en que se ha agotado el requisito de anulación (hablando en términos generales), el laudo ya ha sido sometido a un primer examen, el juez de tutela cumple una función más distante, y pasa a controlar si, al examinarse las causales en el recurso, no se advirtió alguna vulneración de tipo iusfundamental. Con todo, se insiste, en que no debe pasarse por alto que en ambos casos, "[...] la sede de tutela no puede convertirse en un nuevo espacio procesal para reexaminar las cuestiones jurídicas y fácticas que fueron objeto del proceso arbitral" ${ }^{\prime 1}[. .$.$] Como corolario de lo anterior se tiene$ que, con miras a que la acción de tutela no se convierta en una instancia adicional, más en tratándose de la justicia arbitral que se aparta voluntariamente de la jurisdicción ordinaria, y que se respete el margen de decisión de los árbitros, la actuación del juez de tutela debe limitarse a las afectaciones directas de derechos fundamentales. Y esta exigencia se hace más estricta en los casos en que se ha agotado el requisito de subsidiariedad por tratarse de afectaciones que coinciden con las causales que sirvieron de argumentos para llevar el recurso de anulación; de modo que la actuación del juez de amparo debe restringirse a determinar si el derecho al debido proceso se ha protegido en la sentencia de anulación, guardando distancia con los aspectos concretos del laudo ${ }^{92}$. cialmente el recurso de anulación cuando ninguna de las partes tenga su domicilio o residencia en Colombia. 
- De este modo, si las partes hubieran renunciado al recurso de anulación del laudo, el juez de tutela podría revisar si se ha violado o no el orden público internacional, pues este cobija la protección de derechos fundamentales. Sin embargo, no podría revisar sustancialmente el laudo ni invadir el núcleo del principio de habilitación. De hecho, la ley colombiana -artículo 107 de la Ley 1563 del 2012-y la Constitución Política -artículo 116- restringen virtualmente toda posibilidad de revisión, por parte del juez, de los méritos del laudo al ejercer un control de validez, situación que se extiende a la acción de tutela. Por lo anterior, y a falta entonces del recurso de anulación, se propone que la noción de orden público internacional, aplicable en la acción de tutela, sea únicamente la de carácter procesal y no la de carácter sustantivo.

- El orden público internacional, como causal de anulación del laudo, también se limitaría al de carácter procesal. No en vano, el juez no puede pronunciarse sobre el fondo del litigio por expresa disposición legal.

- Así, si las partes no hubieran renunciado al recurso de anulación en el arbitraje internacional, dicho recurso se debe agotar. Después de ello, el juez de tutela, al efectuar un control "menos intenso", necesariamente daría deferencia a la decisión de los árbitros, razón por la cual su valoración de las circunstancias tendría que ser mínima, residual y circunscrita únicamente a la sentencia que resolviese el recurso de anulación. Bajo este contexto notablemente restringido, el único requisito específico del amparo sería la vía de hecho por defecto orgánico.

- En este orden de ideas, y por vía jurisprudencial, se tendría un régimen de procedencia armonizado y restringido para la acción de tutela contra laudos arbitrales en Colombia. Este consultaría los principios de aplicación territorial y supremacía territorial de la Constitución Política, como también el principio constitucional de la habilitación y la naturaleza misma del arbitraje.

Los planteamientos anteriores retoman los lineamientos dados por la Corte Constitucional frente a la procedencia de la acción de tutela contra laudos arbitrales. De ahí que esta última pudiera introducir algunos ajustes puntuales a su jurisprudencia, utilizando sus propias herramientas.

En últimas, la propuesta planteada recoge la naturaleza mixta del arbitraje, pues este depende de la voluntad de las partes, pero concluye con un acto jurisdiccional que hace tránsito a cosa juzgada. La idea central de esta propuesta consiste 
entonces en tutelar real y efectivamente el principio constitucional de la habilitación, sin perjuicio del ámbito objetivo de aplicación de la Constitución Política a las decisiones arbitrales.

\section{Referencias}

Abanto, Jaime David. "El arbitraje en las sentencias del tribunal constitucional y la procedencia del recurso de amparo contra laudos arbitrales". Revista Peruana de Arbitraje, vol. 3 Perú: Editorial Jurídica Grijley, 2006.

Born, Gary. International Commercial Arbitration, vol. 1. Kluwer Law International, 2009.

Caivano, Roque. "Arbitraje y constitución”, Arbitraje y constitución, vol. 1. Asociación Latinoamericana de Arbitraje (2020-2021).

Cárdenas, Juan Pablo. "Las causales para negar el reconocimiento de un laudo que pueden ser declaradas de oficio". Congreso Internacional de Arbitraje. Bogotá, abril del 2005.

Código Judicial de Bélgica.

Código de Procedimiento Civil de Alemania.

Código de Procedimiento Civil de Francia.

Comisión de las Naciones Unidas para el Derecho Mercantil Internacional (CNUDMI-Uncitral). Ley Modelo de Uncitral sobre Arbitraje Comercial Internacional, 1985 y 2006.

Comisión de las Naciones Unidas para el Derecho Mercantil Internacional (CNUDMI-Uncitral). Compendio sobre la Ley Modelo de Uncitral sobre Arbitraje Comercial Internacional, 2012.

Comisión Redactora de la Convención de Nueva York. Reporte de la Comisión para la Ejecución de Laudos Arbitrales Internacionales. Documento ONU E/2704 y E/AC.42/4/Rev.1, del 28 de marzo de 1955.

Constitución Política de Colombia.

Convención de Nueva York de 1958 sobre Reconocimiento y Ejecución de Sentencias Arbitrales Extranjeras.

Consejo de Estado de Colombia. Sección Tercera. Sentencia del 27 de febrero del 2020. 
Corte Constitucional de Colombia. Sentencias C-242 de 1997.

Corte Constitucional de Colombia. Sentencia C-347 de 1997 (y Salvamento de Voto del magistrado Eduardo Cifuentes).

Corte Constitucional de Colombia. Sentencia C-330 del 2000.

Corte Constitucional de Colombia. Sentencia C-590 del 2005.

Corte Constitucional de Colombia: Sentencia SU-174 del 2007.

Corte Constitucional de Colombia: Sentencia T-244 del 2007.

Corte Constitucional de Colombia: Sentencia C-378 del 2008.

Corte Constitucional de Colombia: Sentencia SU-033 del 2008.

Corte Constitucional de Colombia: Sentencia T-058 del 2009.

Corte Constitucional de Colombia. Sentencia T-225 del 2010.

Corte Constitucional de Colombia. Sentencia SU-817 del 2010.

Corte Constitucional de Colombia: Sentencia T-466 del 2011.

Corte Constitucional de Colombia. Sentencia C-535 del 2012.

Corte Constitucional de Colombia: Sentencia SU-500 del 2015.

Corte Constitucional de Colombia: Sentencia SU-556 del 2016 (y Salvamento de Voto del magistrado Alejandro Linares).

Corte Constitucional de Colombia: Sentencia C-674 del 2017.

Corte Constitucional de Colombia. Sentencia SU-033 del 2018.

Corte Constitucional de Colombia. Sentencia T-354 del 2019 (y Aclaración de Voto del magistrado Antonio José Lizarazo).

Corte Suprema de Justicia de Colombia. Sala de Casación Civil. Sentencia del 28 de febrero de 1968. G. J. XLVII.

Corte Suprema de Justicia de Colombia. Sala de Casación Civil. Sentencia del 27 de julio del 2011.

Corte Suprema de Justicia de Colombia. Sala de Casación Civil. Sentencia del 24 de junio del 2016.

Corte Suprema de Justicia de Colombia. Sala de Casación Civil. Sentencia del 7 de septiembre del 2016.

Corte Suprema de Justicia de Colombia. Sala de Casación Civil. Sentencia del 25 de enero del 2017. 
Corte Suprema de Justicia de Colombia. Sala de Casación Civil. Sentencia del 12 de julio del 2017.

Corte Suprema de Justicia de Colombia. Sala de Casación Civil. Sentencia del 19 de diciembre del 2018.

Corte Suprema de Justicia de Colombia. Sala de Casación Civil. Sentencia del 15 de enero del 2019.

Corte Suprema de Justicia de Argentina. Sentencia del caso Meller Comunicaciones S.A. U.T.E. $v$ Empresa Nacional de Telecomunicaciones, 5 de noviembre del 2002.

Cremades, Bernardo. "El arbitraje en la doctrina constitucional española". Lima Arbitration, n. 1 (2006).

CRW Joint Operation v. PT Perusahaan Gas Negara (Persero) TBK, Court of Appeal [2011] SGCA 3 (Singapur).

Cuarto Tribunal Colegiado en Materia Civil de México. Exp DC 4/2014. Caso Conproca.

De Jesús, Alfredo. "La Sala Constitucional y el arbitraje comercial: hacia un régimen racional del control judicial del laudo arbitral en el derecho venezolano". Revista Peruana de Arbitraje, vol. 3 Perú: Editorial Jurídica Grijley, 2006.

English Arbitration Act de 1996

Ley 19971 del 2004 de Chile.

Ley 39 de 1990 de Colombia.

Ley 1563 del 2012 de Colombia

Ley 60 del 2003 de Arbitraje de España

Ley de Arbitraje del Perú del 2008.

Reglamento de Arbitraje de la Cámara de Comercio Internacional (CCl) del 2021.

Reglamento de Arbitraje de la Corte Internacional de Arbitraje de Londres (LCIA) del 2020.

Reglamento de Arbitraje del International Centre for Dispute Resolution (ICDR) del 2021.

Reglamento de Arbitraje Comercial Internacional del Centro de Arbitraje y Conciliación de la Cámara de Comercio de Bogotá.

Reglamento de Arbitraje del Centro de Arbitraje de la Cámara de Comercio de Lima. 
Reglamento de Arbitraje del Centro Internacional de Arbitraje de Madrid.

Flores, Cecilia. "Precedente judicial: los árbitros no son considerados como autoridad para efectos del juicio de amparo". Revista del Club Español de Arbitraje. España: Club Español de Arbitraje, Wolters Kluwer, 2018.

Follonier-Ayala, Alejandro. "Constitucionalización del arbitraje en América Latina". Revista del Club Español de Arbitraje. España: Club Español de Arbitraje, Wolters Kluwer, 2015

Fouchard, Phillipe, Emmanuel Gaillard y Berthold Goldman. International Commercial Arbitration. La Haya: Kluwer Law International, 1999.

Gaviria, Juan Antonio y Néstor Londoño. "El conflicto entre la acción de tutela colombiana y la Convención de Nueva York sobre reconocimiento y ejecución de las sentencias arbitrales extranjeras". En Reconocimiento y ejecución de sentencias arbitrales extranjeras en España y en Latinoamérica, editado por Katia Fach y Ana Mercedes López. Madrid: Tirant Lo Blanch, 2019.

Ghestin, Jacques. Traité de Droit Civil. Les Obligations. Le Contrat: Formation 3 Edition. París: Librairie Genérale de Droit et Jurisprudence (LGDJ), 1993.

González de Cossío, Francisco. "Mexico's fantastic three: a pro-arbitration trilogy". Arbitration International, n. 33 (2017).

-. "National Report for Mexico (2018 through 2019)". ICCA International Handbook on Commercial Arbitration. Kluwer Law International \& ICCA, 2020.

-. "Arbitraje y procesos constitucionales: agua y aceite". Arbitraje y Constitución, vol. 1. Asociación Latinoamericana de Arbitraje (2020-2021).

Hebei Import and Export Corporation -v- Polytek Engineering Co. Ltd [1999] 2 HKC 205 (Hong Kong).

Hinojosa, Rafael. "La impugnación del laudo en la ley española de 2003". Revista Peruana de Arbitraje, vol. 3 Perú: Editorial Jurídica Grijley, 2006.

Holguín Holguín, Carlos. "La noción de orden público en el derecho internacional privado". IDEA-El derecho de los negocios internacionales. Bogotá: Universidad Externado de Colombia, 1991.

Ibáñez, Jorge Enrique. La acción de tutela contra laudos arbitrales. Bogotá: Pontificia Universidad Javeriana, De Palma y Grupo Editorial Ibáñez, 2009.

Lew, Julian. "Determination of arbitrators' jurisdiction and the public policy limitations on that jurisdiction". Contemporary Problems in International Arbitration. Londres: CCLS, 1986. 
Mayer, Pierre y Audley Sheppard. "Informe final de la Asociación de Derecho Internacional acerca del orden público como una prohibición para la ejecución de los laudos arbitrales". Revista Internacional de Arbitraje, vol. I. Bogotá: Legis, Universidad Sergio Arboleda, 2004.

Mustill, Lord. "Comments and conclusions". Conservatory \& provisional measures in international arbitration. 9th Joint Colloquium. Publicación CCI 519, 1993.

Parson \& Whittemore Overseas Co. Inc. v. Societé Générale de l'Industrie du Papier Rakta and Bank of America 508 F.2d 969 (2 Cir., 1974) (Estados Unidos).

PT Perusahaan Gas Negara (Persero) TBK v. CRW Joint Operation, High Court, Singapore, 20 de julio del 2010, [2010] SGHC 202 (SA) (Singapur).

Redfern, Adam, Martin Hunter, Nigel Blackaby y Constantine Partasides. Redfern and hunter on international arbitration. Oxford: Oxford University Press, 2015.

Remón, Jesús. "La anulación del laudo: el marco general, el pacto de exclusión y el orden público". Revista del Club Español de Arbitraje. España: Club Español de Arbitraje, Wolters Kluwer, 2006.

Rivera, Julio César. "La revisión judicial del laudo arbitral en Argentina: aspectos constitucionales". Revista Arbitraje PUCP, n. ${ }^{\circ} 4$ (2014).

Salazar, Bernardo. "Tutela contra laudos arbitrales en Colombia". Arbitraje y Constitución, vol. 1. Asociación Latinoamericana de Arbitraje (2020-2021).

Santistevan de Noriega, Jorge. "Arbitraje y jurisdicción desde la perspectiva del Tribunal Constitucional del Perú". Revista Peruana de Arbitraje, vol. 3. Perú: Editorial Jurídica Grijley, 2006

Silva Romero, Eduardo. "Una obligación de hacer: someter el litigio al arbitraje"; y "Una obligación de no hacer: no someter los litigios a la jurisdicción estatal", en El contrato de arbitraje. Bogotá: Legis, Universidad del Rosario, 2005.

Sheppard, Audley. "Public policy and the enforcement of arbitral awards: Should there be a global standard?". Transnational Dispute Management, vol. 1 (2004).

Suescún, Jorge. Derecho privado: estudios de derecho civil y comercial contemporáneo, T. II Bogotá: Legis, Ediciones Uniandes, 2003.

Talero Rueda, Santiago. Arbitraje comercial internacional: instituciones básicas y derecho aplicable. Bogotá: Temis, Ediciones Uniandes, 2008. 
-. "La agencia comercial y los sistemas de distribución en el arbitraje internacional". Revista de Derecho Privado, Universidad de los Andes, n. ${ }^{\circ} 44$ (2010)

-. "Extensión del pacto arbitral a no signatarios: perspectivas en la nueva Ley Peruana de Arbitraje”. Lima Arbitration, n.․ 4 (2010-2011).

-. "Salient Features of the Colombian Constitutional Court's review of awards in international arbitrations". Kluwer Arbitration Blog. Wolters Kluwer, 28 de noviembre del 2019. http://arbitrationblog.kluwerarbitra tion.com/2019/11/28/salient-features-of-the-colombian-constitutio nal-courts-review-of-awards-in-international-arbitrations/

The United Mexican States v. Metalclad Corporation. Corte Suprema de British Columbia. Sentencia del 2 de mayo del 2001. (Canadá).

Tribunal Constitucional de España. Sentencia del 15 de abril de 1986.

Tribunal Constitucional de España. Sentencia 176/1996 del 11 de noviembre de 1996.

Tribunal Constitucional de España. Sentencia 155/2009 del 25 de junio del 2009.

Tribunal Constitucional del Perú. Sentencia del 11 de septiembre del 2011, caso María Julia.

Tribunal Constitucional de España. Sentencia 46/2020 del 15 de junio del 2020.

United Steel Workers of America v. Warrior and GulfNavigation Co., 36 US 574, 582 (1960) (Estados Unidos).

Zuleta, Eduardo y María Camila Rincón. “Colombia's Constitutional Court declares that constitutional injunctions (tutela) can be upheld against awards in international arbitration". Kluwer Arbitration Blog. Wolters Kluwer, 4 de noviembre del 2019. http://arbitrationblog.kluwe rarbitration.com/2019/11/04/colombias-constitutional-court-decla res-that-constitutional-injunctions-tutela-can-be-upheld-against-award s-in-international-arbitration/ 